\title{
EL BILBAO DEL PROGRESO: GESTIÓN MUNICIPAL Y SERVICIOS PÚBLICOS (1876-1920)
}

\section{THE BILBAO OF PROGRESS: MUNICIPAL MANAGEMENT AND PUBLIC SERVICES (1876-1920)}

\author{
Susana Serrano Abad \\ Universidad del País Vasco/Euskal Herriko Unibertsitatea
}

Entregado el 27-12-2014 y aceptado el 4-5-2015.

Resumen: La sociedad urbana en ascenso se manifestaba en Bilbao en las últimas décadas del XIX a través de un dinámico crecimiento económico, un fuerte incremento demográfico y la extensión territorial de la ciudad. Sin embargo, vio una respuesta lenta a sus demandas de servicios básicos (agua, saneamiento, sanidad, vivienda). El ritmo al que se fueron incorporando y ampliando estos servicios públicos fue lento y atenuado, de manera que, hasta la primera década del siglo xx, Bilbao no dispuso de una red de servicios públicos acorde con el volumen de su población y con los criterios de modernidad.

Palabras clave: Historia urbana, modernidad, gestión municipal, servicios públicos.

Summary: In the last decades of the XIX century, the rising urban society in Bilbao was manifested through a dynamic economic growth, a big demographic increase and a territorial extension of the city. Nevertheless, the way that public services (water, dumping, health, housing), the most basic ones, were established and extended was so slow, until the end of the last decade of the XX century. Bilbao had not public services available according to the population and to the standards of modernity that were imposed.

Key words: Urban History, modernity, municipal management, public services. 
Las ciudades fueron los focos difusores de los cambios económicos, sociales, políticos y culturales que se vivieron en la España de la Restauración. No obstante, convivieron en dicha época realidades bien distintas, con dinámicas particulares, que impiden la uniformización del proceso de los espacios que evolucionaron hacia una sociedad urbana y entraron a participar en los que hemos denominado Modernidad ${ }^{1}$. Durante el último tercio del siglo XIX, Bilbao pasó a representar el modelo de la ciudad industrial, y su configuración ha requerido del análisis de la evolución demográfica, la extensión y la planificación urbana, la distribución y organización de los usos del suelo, las infraestructuras, la organización territorial. Los resultados de este estudio de enfoque multidisciplinar han quedado plasmados desde hace dos décadas en dos publicaciones que destacamos, Bilbao en la Formación del País Vasco Contemporáneo. Economía, población y ciudad y Los orígenes de una metrópoli industrial: La Ría de Bilbao.

Estas transformaciones urbanas de Bilbao en los siglos XIX y XX también han precisado del estudio de las élites locales, entendidas éstas como factores causales, inductores y modeladores de los procesos de construcción y modernización de las ciudades ${ }^{2}$. Son estas élites locales los agentes protagonistas y los gestores de los procesos de configuración urbana, los líderes de los cambios que se van introduciendo en el espacio urbano al ritmo que marcan los imperativos sociales y económicos. Teniendo en cuenta que han controlado las instituciones de poder, sin duda de sus ideas, estrategias y actuaciones se deriva la formación de la ciudad. En este sentido, ha destacado H. Capel el «giro institucionalista» o el «énfasis institucional» que se ha vivido en las ciencias sociales, en alusión al hecho de que son más conscientes de la importancia de las instituciones, unas instituciones que modelan la sociedad y el territorio ${ }^{3}$.

A través de la gestión municipal, además, es posible valorar la distancia entre la ciudad soñada y la ciudad real, la realizada, producto del

${ }^{1}$ L. E. Otero y R. Pallol, «El Madrid moderno, capital de una España urbana en transformación, 1860-1931», en Historia Contemporánea, n. ${ }^{\circ}$ 39, 2009 (II), pp. 548-549.

2 P. Carasa, «Representatividad de las élites municipales y transformación urbana (Valladolid 1810-2000)», en M. González Portilla, J. M. B Beascoechea y K. Zarraga (eds.), Procesos de transición, cambio e innovación en la ciudad contemporánea, Servicio Editorial de la Universidad del País Vasco, Bilbao, 2011, p. 606.

${ }^{3}$ H. Capel, «González Ceballos, Sara. La política de escalas en Bilbao: la construcción sociopolítica de un Área Metropolitana», en Biblio 3W Revista Bibliográfica de Geografía y Ciencias Sociales, Vol. IX, n. ${ }^{\circ}$ 486, 2004, p. 18. 
juego de intereses económicos, sociales y municipales. De manera que el Ayuntamiento, por ser la institución que gobierna la ciudad, que dirige la toma de decisiones sobre la misma, y el alcalde, como su representante, han constituido el objeto central del análisis en la obra dirigida por J. Agirreazkuenaga Bilbao desde sus alcaldes. Diccionario biográficos de los alcaldes de Bilbao, que consta de varios volúmenes, en los que se sigue el recorrido de la gestión municipal bilbaína desde 1836 a 1979.

Desde esta perspectiva, la presente investigación trata de avanzar en la definición del proceso de urbanización a partir de la comprensión del propio concepto de urbanización, que supone la creación de unos servicios públicos que permitan el desarrollo de la vida urbana y la atención de las necesidades básicas de los ciudadanos. Enlaza dicho concepto con las funciones que está llamada a asumir la moderna administración local a finales del siglo XIX, una administración entendida como servicio a la población, huyendo del marcado carácter político que había dominado en períodos anteriores, producto de las luchas de las diferentes facciones dentro del contexto de la revolución liberal. Es, por tanto, que se impone valorar el papel de la administración local en el impulso de los servicios públicos que demandaba una sociedad urbana en ascenso. Esto es, no se trata tanto de cuantificar cuántos hospitales, cuántas escuelas o cuántos mercados se abrieron por iniciativa pública, sino como de conocer la respuesta que los gestores municipales fueron dando a las demandas que eran reclamadas en la sociedad.

\section{Los años de los proyectos (1876-1890)}

En el siglo XIX los partidarios de la revolución liberal y sus oponentes contrarrevolucionarios, los llamados carlistas, protagonizaron una guerra civil que, en diversos episodios, se prolongó a lo largo de cuarenta años desde la muerte de Fernando VII (1833). En el País Vasco, el enfrentamiento incluyó también el debate sobre la conservación del régimen foral propio (autogobierno político, económico-administrativo) en el marco constitucional liberal español ${ }^{4}$.

${ }^{4}$ El panorama político se complicó y, entre los liberales, surgieron diferencias sobre el tipo de liberalismo y su posición frente al régimen foral. Entre los liberales bilbaínos, las corrientes político-ideológicas mayoritarias fueron: la que agrupaba a los liberales fueristas progresistas, que defendían la Constitución y, al mismo tiempo, reivindicaban de los fueros 
Durante la última guerra carlista (1872-1876), Bilbao se convirtió en escenario de combates y la población fue sometida a un duro sitio que se prolongó cuatro meses (28.12.1873-2.05.1874). Al concluir la contienda, la corporación municipal hubo de hacer frente a la reconstrucción de la ciudad, así como al estado crítico de la hacienda local, sobre la que pesaba una elevada deuda derivada de los gastos de defensa y servicios especiales ${ }^{5}$. Pese a estas críticas circunstancias, apremió la tramitación del proyecto de Ensanche de Bilbao, ya redactado, pero cuya gestión ante el gobierno se hallaba paralizada por el desarrollo de la contienda. Tras el traslado de una comisión a Madrid, el Plan de Ensanche fue aprobado por R. D. de 30 de mayo de 1876.

En febrero había concluido la guerra y en julio se aprobaba la Ley de abolición del régimen foral vasco, que generó una escisión en el seno del grupo liberal de Bilbao, entre los que propugnaban la adecuación a la administración y leyes españolas y los que se resistían a cambiar los organismos forales. A comienzos de 1877, el Ayuntamiento, tras ser requerido para proceder a las tareas de alistamiento de mozos en cumplimiento de la Ley de Reemplazo del ejército, manifestó su intención de no intervenir, motivo por el cual fue declarado en rebeldía. En el curso de estos acontecimientos, dimitió el alcalde Felipe Uhagón y, tras la fugaz presidencia de Agustín María Obieta (15.02.-31.03.1877), Pablo Alzola era designado para asumir dichas funciones (1877-1879), en un momento en que se iniciaba el proceso de cambio político-administrativo y la puesta en marcha de la construcción de la nueva ciudad.

Con su gestión al frente de la corporación municipal arrancaba la creación de la nueva población en la margen contraria de la ría, en la vega de Abando, terrenos que habían sido anexionados en 1870 y en los que se irían incrustando infraestructuras y equipamientos públicos, así como un amplio y moderno puerto. Sin embargo, en adelante iban a confluir los problemas generados por una crisis de crecimiento que, de forma patente,

fundamentalmente la conservación del sistema fiscal autónomo, y la de los liberales fueristas moderados, que sostenían la defensa íntegra del régimen foral (autogobierno político, económico-administrativo) y Constitución. La mayoría de los alcaldes del período 18341876 perteneció a esta última tendencia.

5 J. Agirreazkuenaga (Dir.), Bilbao desde sus alcaldes. Diccionario biográfico de los alcaldes de Bilbao y gestión municipal, en tiempos de revolución liberal e industrial Vol. 1: 1836-1901, Ayuntamiento de Bilbao, Bilbao, 2002, p. 478. El balance desglosado de la deuda del Ayuntamiento era en marzo de 1876: por gastos ordinarios, 1.500 .000 pts., y la especial de guerra para defensa y gastos derivados, aproximadamente 2.600 .000 pts. 
se vislumbraban en la ciudad vieja desde al menos veinticinco años atrás, con las manifestaciones de mayor impacto derivadas de una industrialización que iría cobrando fuertes dimensiones a lo largo del último cuarto del XIX. La falta de viviendas, el hacinamiento, el deterioro de la sanidad, de la higiene y de la salud pública, la insuficiencia de los suministros de agua, de depósitos y almacenes,... habían alcanzado durante el tercer cuarto de siglo proporciones que impedían la simple reforma de la ciudad heredada. La extensión territorial y la entrada en un nuevo ciclo de expansión económica creaban la coyuntura favorable para la mejora, ampliación y diversificación de infraestructuras, equipamientos y servicios públicos ya en clave de modernidad, a nivel técnico y de gestión. Sin embargo, estas transformaciones tuvieron un lento discurrir desde la formulación de las propuestas hasta la plasmación material de los proyectos durante los años iniciales del siglo XX, debido a la conjunción de factores, algunos de los mismos propios y específicos de Bilbao (anexiones, fiscalidad, entramado institucional, propiedad).

Los años de 1876 a 1890 fueron años de tanteos, de proyectos, de actuaciones, la mayoría de ellas, sin carácter definitivo en la conformación de la red de servicios públicos de la ciudad moderna, algunas de las mismas impuestas por la urgencia. En la gestión municipal, no faltó el liderazgo de técnicos cualificados, expertos en la administración y/o de individuos con una elevada capacidad y nivel de relaciones. Fallaron, en general, las previsiones, realizadas en función de unos ritmos de crecimiento de la población insospechados, difíciles de prever, como también fallaron los recursos, limitados e incapaces para financiar capítulos del presupuesto municipal de gastos, año a año, más abultados (deuda, personal administrativo, obras públicas, instrucción y beneficencia).

La tasa media anual de crecimiento de la población de Bilbao fue de un 4,29\% en la década 1877-1887 y todavía de un elevado 3,39\% entre 1887 y $1900^{6}$. De nada sirvieron las previsiones para cubrir el suministro de agua, las necesidades de vivienda o los servicios hospitalarios, realizadas en función de los niveles de crecimiento de décadas anteriores $(1,77 \%)$. El propio Pablo Alzola, exalcalde de la villa, reconocería en torno a 1890 que enseñaba «la experiencia que todos los errores han sido hasta ahora por cálculos demasiado bajos» del incremento de la pobla-

${ }^{6}$ M. González Portilla (Ed.), Los orígenes de una metrópoli industrial: La Ría de Bilbao, Fundación BBVA, Bilbao, 2001, Vol. I, p. 96. 
ción, motivo por el cual valía «la pena reflexionar acerca de los perjuicios que puedan originarse en un porvenir nada lejano por la imprevisión y el olvido» ${ }^{7}$.

Errores de previsión difíciles de salvar, más aún, cuando no se disponía de terrenos dentro de los límites jurisdiccionales donde construir equipamientos de gran capacidad, ni tampoco de locales municipales propios, de manera que se impuso la improvisación y la arbitrariedad en la distribución. En cuanto a los presupuestos municipales, que arrastraban la fuerte deuda derivada de la guerra, se dispararon y llegaron a superar para finales de la década de los 80 a los presupuestos provinciales ${ }^{8}$, dado el incremento producido, sobre todo, en gastos de personal y en obras públicas, cuando aún entonces se hallaban paralizadas actuaciones urgentes (traída de aguas, hospital, cementerio). El recurso del empréstito, el recargo de los arbitrios sobre el consumo, nuevos impuestos y las derramas sobre la propiedad no bastaron para controlar un déficit, que fue en aumento.

\subsection{Pablo Alzola, ideólogo de la ciudad nueva}

Por R.O. de 27 de marzo de 1877, era nombrado alcalde Pablo Alzola (1841-1912) ${ }^{9}$, ingeniero de Caminos, Canales y Puertos que, tras su gra-

7 P. Alzola, «Los parques americanos y Bilbao», en Euskal-Erria. Revista Bascongada, t. 29 (1893), p. 229.

8 A.H.F.B. Municipal Bilbao. Bilbao Actas 0339 a 0344 (enero a junio de 1888).

9 A falta de una biografía amplia y global de Pablo Alzola, señalar las siguientes reseñas biográficas sobre el mismo: E. Alonso, «Pablo Alzola y la modernidad», en Bidebarrieta, n. ${ }^{\circ} 4$ (1999), pp. 209-226; E. Alonso, «Pablo de Alzola y Minondo. Ideas y realidad de los Derechos Históricos (1841-1912)», en I Symposium del Instituto de Historia del Derecho de Vasconia: Protagonistas y artífices del derecho de los territorios de Vasconia. Publicado en Notitia Vasconiae, 1 (2002), pp. 411-434; J. A. Ereño y A. Isasi, La cuestión del Ensanche de Bilbao. Miguel de Unamuno y Jugo. Pablo de Alzola y Minondo, Ayuntamiento de Bilbao, Bilbao, 2000; R. López Atxurra, «Pablo de Alzola. Un Hombre de acción abierto al mundo», en E. Alonso (Ed.), El régimen económico-administrativo antiguo y moderno de Vizcaya y Guipúzcoa, Clásicos de la Hacienda Foral 7, Diputación Foral de Bizkaia y Universidad del País Vasco, Bilbao, 2008, pp. XLV-LXII; S. Serrano, «Alzola Minondo, Pablo», en J. Agirreazkuenaga (Dir), Bilbao desde sus alcaldes. Diccionario biográfico de los alcaldes de Bilbao y gestión municipal en tiempos de revolución liberal..., op. cit., pp. 489-508; S. Serrano, «Pablo Alzola, un perfil biográfico», en E. Alonso (Ed.), El régimen económico-administrativo antiguo y moderno de Vizcaya y Guipúzcoa, Clásicos de la Hacienda Foral 7, Diputación Foral de Bizkaia y Universidad del País Vasco, Bilbao, 2008, pp. XIII-XXXIX. 
duación en Madrid (1863) y el inicio de su carrera profesional en Málaga, había sido destinado en 1869 a Bilbao, donde residía, por tanto, desde hacía tan sólo ocho años. Desde la Jefatura de las Provincias Vascongadas se le encomendó, entre otras cuestiones, la conservación del puerto y ría de Bilbao, al tiempo que fue nombrado Capitán del mismo ${ }^{10}$. Realizó un estudio para mejora de la navegabilidad de la ría y el nuevo Plan de Ensanche de Bilbao, que abordó con Ernesto Hoffmeyer y el arquitecto Severino Achúcarro.

Sin duda, fue obra de Pablo Alzola el epígrafe VI del capítulo III que, en el proyecto de Plan de Ensanche de Bilbao, se dedica al «Ferrocarril, dársena, docks y trazado de los muelles de la ría» ${ }^{11}$, epígrafe que confiere al Plan una particularidad significativa. En él se detallan las obras de encauzamiento de la ría, la construcción de dársenas y de una futura línea ferroviaria hasta Portugalete, ferrocarril de Bilbao a Portugalete del que precisamente Pablo Alzola sería autor de su trazado ${ }^{12}$. Esta arteria que conformaban la ría y el puerto, considerada como el motor de la economía bilbaína, se disponía en el Plan a lo largo de la ribera baja de la vega de Abando. Con estas ideas Pablo Alzola estaba expresando el sentir de la burguesía bilbaína ${ }^{13}$, que veía en la ría y el puerto bilbaíno el elemento clave de la expansión futura y cuyo control pretendía asegurarse. Por su parte la «hermosa meseta» de la vega de Abando, elevada sobre el nivel de la ría y con unas condiciones favorables para la edificación y la salubridad, constituía la reserva para la configuración de un asentamiento residencial de calidad. En este modelo de ensanche que perseguía el equilibrio, fueron proyectados el Parque, paseos, plazas y edificios públicos, si Bilbao había «de ponerse al nivel que por su floreciente comercio y número de habitantes» le correspondía ${ }^{14}$.

En sus ocho años de residencia en Bilbao, Pablo Alzola había captado la dirección que la ciudad debía tomar para encauzar su desarrollo eco-

10 Reseña biográfica de la labor realizada por Pablo de Alzola y Minondo, Bilbao, Imprenta y Encuadernación de la Casa de Misericordia, 1911, p. 14.

11 J. Cárcamo J. (Ed.), Memoria del Proyecto de Ensanche de Bilbao 1876. Alzola, Achúcarro y Hoffmeyer, Colegio Oficial de Aparejadores y Arquitectos de Vizcaya y Ayuntamiento de Bilbao, Bilbao, 1988, pp. 102-104.

12 P. A. Novo, La explotación de la red ferroviaria del País Vasco. Mercado y Ordenación del Territorio, Universidad del País Vasco, Bilbao, 1995, p. 316.

13 Pablo Alzola alcanzaba en 1883 la presidencia del Comité Liberal de Bilbao, más tarde abandonaba las filas del Partido Liberal para ingresar en el Partido Conservador.

14 J. Cárcamo (Ed.), Memoria del Proyecto de Ensanche..., op. cit., p. 100. 
nómico, al tiempo que su nivel de relaciones le permitía acceder a la Alcaldía. El nombramiento de Pablo Alzola como alcalde se producía en un momento histórico, como él lo calificaba ${ }^{15}$, consciente de las oportunidades que brindaba. El día en que tomaba posesión del cargo, 1 de abril de 1877, anunciaba la inauguración de una nueva etapa en la administración municipal, en el momento histórico en que, tras 80 años marcados por la guerra y la inestabilidad, llegaba la paz, cuyos beneficios había que aprovechar; en que el largo proceso de siglos para conseguir la ampliación territorial de la villa había reportado la anexión parcial de las anteiglesias de Abando y de Begoña (1870), y en que el crecimiento económico y demográfico de Bilbao era ya palpable.

Seguidamente, pasaba a definir las nuevas funciones que estaban llamados a asumir los ayuntamientos. Fruto de su gestión, sería la ciudad, extensa en su organización territorial, ordenada y bella en lo arquitectónico, e instruida y equipada en lo social. Reclamaba, por ello, la acción directa del Municipio, «esencialmente llamado a ser reformador» en un doble sentido: en primer lugar, por el carácter administrativo que había de asumir, huyendo del «yugo político» al que habían estado sometidos los ayuntamientos años atrás, y en segundo lugar, por la misión que debía guiar a la corporación, que no era otra que «proveer las necesidades públicas del vecindario», morales, intelectuales y materiales. El carácter reformador que anteponía Pablo Alzola, al confiar en la misión esencialmente administrativa del Ayuntamiento, cobraba especial significado porque hasta 1876 las élites dirigentes habían trasladado al consistorio la lucha que la revolución liberal suponía. El escenario municipal era el medio donde desarrollar su identidad política e intentar la implantación de su facción del liberalismo.

La idea del desarrollo de la ciudad era la meta a alcanzar que proponía el alcalde, máxime cuando se trataba de una población como era «la metrópoli de Vizcaya», que contaba con pueblos, situados a lo largo de la ría entre Bilbao y Portugalete, que veían aumentar su vida y movimiento como si fueran barrios de aquella primera villa. Bilbao y lo que se llamaba puerto no bajaban de los 50.000 habitantes, siendo ya la capital más importante del norte de España ${ }^{16}$. Constituía la formulación primera de la dimensión metropolitana de Bilbao, de su proyección más

15 A.H.F.B. Municipal Bilbao. Bilbao Actas 0310 (1877-1878). Discurso de toma de posesión.

16 A.H.F.B. Municipal Bilbao. Bilbao Actas 0310 (1877-1878). 
allá de los puros límites administrativos y motor de su área de influencia. En su concepción de la nueva ciudad subyacen aspectos que serán cruciales en el futuro: por un lado, la visión de la que había de ser la organización territorial de Bilbao, ciudad central que extendía su ámbito de influencia por la ría hacia El Abra, y por el otro, la condición portuaria de la ciudad, puerto que constituía el motor del futuro desarrollo económico y que actuaría al mismo tiempo como eje vertebrador de la futura metrópoli bilbaína, al que se irían ensamblando ferrocarriles e industrias.

Aunque no dedicara ninguno de sus escritos, numerosos y de variada temática por otro lado, a exponer con mayor concreción su modelo metropolitano, las ideas contenidas en ciertos artículos permiten intuir el indudable referente que para él constituían las ciudades norteamericanas, creadas «con sujeción a planos, en los que se admira la grandiosidad de las miras expansivas $[\ldots] »^{17}$. Incidía en la idea de articular una red viaria y ferroviaria que favoreciera el enlace entre la ciudad central y sus diferentes unidades, que Pablo Alzola materializó con la entrada en funcionamiento del ferrocarril Bilbao-Portugalete: «La vía férrea de Portugalete se asemeja por la densidad de la población y los elementos de vida de la zona que recorre, a los ferrocarriles metropolitanos del interior y arrabales de las grandes ciudades» ${ }^{18}$. De la organización interna de la ciudad central del área metropolitana, destacaba la articulación de un distrito de negocios, sede de edificios donde albergar bancos, escritorios y oficinas, para así «evitar la pérdida de tiempo inherente a los largos recorridos», rodeado de barrios residenciales de baja densidad y de un cinturón verde urbano con paseos y parques encadenados. Y aunque sobresale, en sus referencias, la ciudad de Chicago, admitía que se pudiera dar como respuesta que ni «estamos en el país de los yankees, ni Bilbao es Chicago», pero similar organización se apreciaba al descender a escalas menores.

En función de esta idea de progreso, Pablo Alzola estableció unas claras directrices a seguir durante el bienio de su mandato: difusión de la instrucción pública, a nivel de la instrucción primaria y, en mayor medida, de la orientada a las artes y oficios, que constituían la especialidad local;

17 P. Alzola, «Los parque americanos y Bilbao»..., op. cit., p. 226.

18 Memoria presentada por el Consejo de Administración del Ferrocarril de Bilbao a Portugalete a la Junta General de Accionistas, celebrada el día 30 de mayo de 1890, Bilbao, Imp. de la Casa de Misericordia, 1890, p. 8. 
construcción de edificios públicos, ejecución del Ensanche y mejora y modernización de la ría y puerto de Bilbao, obras éstas dos últimas a las que había que dirigir los recursos disponibles, pese a los problemas derivados de la deuda contraída en la última guerra ${ }^{19}$.

En 1878 se constituía la Junta Local de Enseñanza, se iniciaba la formación de la biblioteca municipal y se procedía a la apertura de la Academia de música. Un año después, abría sus puertas la Escuela de Artes y Oficios, bajo el patronato de la Diputación y el Ayuntamiento. El nombramiento de la Junta de Ensanche que prevenía la ley fue inmediato a la constitución de la corporación municipal (12.04.1877). Una vez constituida la Junta de Obras del Puerto (1876) y designado el ingeniero director que había de encargarse de las obras de mejora de la ría y puerto de Bilbao (1877), Evaristo Churruca, compañero de promoción de Pablo Alzola, se iniciaba una nueva etapa marcada por la expansión y modernización de las estructuras portuarias. Al tiempo que la ciudad iniciaba su expansión por los terrenos de la margen izquierda de la ría, el puerto acometía la propia siguiendo el mismo eje, de manera que sus gestores manifestaban una comunidad de intereses. Dichas obras fueron acometidas a lo largo de la década de los años 80 sin tropezar con los obstáculos del Ensanche, de modo que fue rápido el desarrollo portuario alcanzado en el sector interior de la ciudad (Arenal-Ripa).

\subsection{Las urgencias del primer Plan general de Obras Públicas (1881)}

Bajo la Alcaldía de Eduardo Victoria de Lecea ${ }^{20}$, conocedor de la problemática de la ciudad, vino la elaboración de un Plan general de Obras Públicas, el primer plan de actuaciones programado por el Ayuntamiento, que nacía de inmediato tras la toma de posesión de aquel, el 1 día de julio de 1881. Durante su mandato, contó con la colaboración especial de Ma-

19 A.H.F.B. Municipal Bilbao. Bilbao Actas 0310 (1877-1878).

${ }^{20}$ Abogado y diplomático destinado en Bruselas, abandonó dicho cuerpo en 1864 a la muerte de su padre, Federico Victoria de Lecea, exalcalde de Bilbao. A su regreso a Bilbao, era nombrado en 1867 para presidir el Ayuntamiento de la villa. Gestionó personalmente el proyecto de ampliación de límites jurisdiccionales ( R.O. de 30 de junio de 1867) y abordó el inicio de la reforma del casco urbano y Bilbao la Vieja. Tras el bienio de 1881-1883, prolongó su mandato hasta 1885, dado su nombramiento por R.O. de 26 de junio de 1883. Militó en el Partido Liberal. 
nuel Lecanda ${ }^{21}$, que prestó asesoramiento en temas jurídicos, y con Fernando L. Ybarra ${ }^{22}$, que demostró ser un hábil gestor en la administración local e individuo clave en las reformas practicadas fundamentalmente en el campo sanitario-benéfico.

En el mencionado Plan general de Obras Públicas, fueron clasificadas como líneas de actuación prioritarias: en primer lugar, la ampliación y mejora de los servicios municipales, fundamentalmente en materia de educación, sanidad y beneficencia, y en segundo lugar, la atención a los barrios emergentes de condición obrera (San Francisco y el Cristo). El Plan contemplaba obras de nueva construcción tan cruciales como dos hospitales, dos salas-cuna, un cementerio, casa consistorial, teatro, puente de enlace entre el casco antiguo y los barrios obreros (La Merced) y depósitos municipales.

El informe de la Junta local de primera enseñanza había sido rotundo: de las doce escuelas municipales existentes, tan sólo cinco escapaban de tan desfavorable condición. De ahí el proyecto de reforma que contemplaba la creación de escuelas de párvulos, tanto en los populosos barrios de San Francisco y el Cristo, como en Abando. Como señala M. ${ }^{\mathrm{a}}$ T. Ruiz de Loizaga, en esta primera década de precariedad de los años 80, el ayuntamiento recurría a locales alquilados, hecho del que se derivaban diversos problemas de aglomeración de escolares, malas condiciones de luz y ventilación e inclusive mínimas condiciones pedagógicas. Luego, estas llamadas escuelas serían simples habitaciones o pisos de inmuebles alquilados, no de propiedad municipal ${ }^{23}$.

21 S. Serrano, «Lecanda Mendieta, Manuel», en J. Agirreazkuenaga (Dir.), Bilbao desde sus alcaldes. Diccionario biográfico de los alcaldes de Bilbao y gestión municipal en tiempos de revolución liberal..., op. cit., pp. 515-526. Manuel Lecanda, abogado de profesión, fue Regidor de la Diputación de Bizkaia en 1858-1860, Consultor de dicha institución desde 1870 y alcalde de Bilbao en 1880-1881. Liberal bilbaíno unido por fuertes lazos de amistad a Eduardo Victoria de Lecea.

22 J. M. ${ }^{a}$ Beascoechea, «Ibarra Gutiérrez de Cabiedes, Gabriel María» e «Ibarra Gutiérrez de Cabiedes, Juan María», en J. Agirreazkuenaga (Dir.), Diccionario Biográfico de los Diputados Generales, Burócratas y Patricios de Bizkaia (1808-1876), Juntas Generales de Bizkaia, Bilbao, 1995, pp. 255-263. Fernando Luis Ibarra Arambarri (1845-1888) fue hijo de Gabriel M. ${ }^{a}$ Ibarra Gutiérrez de Cabiedes, comerciante, propietario minero y hombre de negocios, ligado a la siderurgia Nuestra Señora del Carmen, germen de Altos Hornos de Bilbao (1882). Contrajo matrimonio con María de la Revilla Ingunza, hermana de Gregorio de la Revilla, alcalde de Bilbao en 1891-1893.

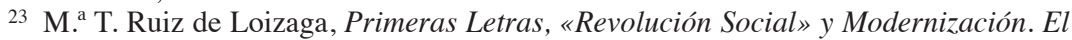
Bilbao de la Restauración 1876-1920, Tesis Doctoral del Departamento de Historia Contemporánea de la Universidad del País Vasco, Leioa, 2009, pp. 164 y ss. 
Un plan ambicioso que no resolvió el grave problema sanitario, derivado del intenso crecimiento demográfico, la escasez de vivienda asequible y las pésimas condiciones de vida en los emergentes barrios obreros. No obstante, sirvió para poner en marcha el proyecto de construcción de un nuevo hospital, cuya gestación siguió un largo y costoso proceso debido en buena parte a las dificultades para encontrar terrenos donde levantar un nuevo centro sanitario de las dimensiones que requería la población bilbaína. Urgía un hospital ${ }^{24}$, aunque desde la corporación municipal se tomaba conciencia de que el hacinamiento y el agua eran las causas prioritarias del deterioro de la salud pública bilbaína.

\section{Tabla 1}

Evolución de las tasas brutas de mortalidad en Bizkaia y Bilbao (1.000 hab.)

\begin{tabular}{lcccccc}
\hline & 1860 & 1887 & 1900 & 1910 & 1920 & 1930 \\
\hline Bizkaia & 26,00 & 27,80 & 26,20 & 19,10 & 18,40 & 13,70 \\
Bilbao & 23,65 & 29,28 & 32,59 & 22,44 & 23,16 & 18,34 \\
\hline
\end{tabular}

Fuente: M. González Portilla (Dir.), Bilbao en la formación del País Vasco Contemporáneo (Economía, población y ciudad), Fundación BBV, Bilbao, 1995, p. 236.

Las deficiencias hospitalarias ya se manifestaron con motivo del cólera de 1854, más adelante quedaron recogidas en la propuesta que el concejal Cosme Echevarrieta realizara en 1873 sobre la necesidad de agilizar la construcción de un nuevo hospital ${ }^{25}$. De nuevo fue suscitado el tema durante la corta Alcaldía de Agustín María Obieta (1877), presidente honorario de la Academia de Ciencias Médicas de Bilbao (1895), así como bajo mandato de Pablo Alzola.

${ }^{24}$ J. M. ${ }^{\text {a }}$ Beascoechea, «La construcción del nuevo hospital en Basurto y su inserción urbana en Bilbao», en M. González Portilla y K. Zarraga Sangroniz (Eds.), Hospital de Bilbao y transición sanitaria. Enfermedad y muerte en Vizcaya, 1884-1936, Ikur S.A., Bilbao, 1998, pp. 161-222. Al viejo Hospital de los Santos Juanes (s. XV), le sucedió el conocido como Hospital Civil de Atxuri, cuyas obras dieron comienzo en 1818, siguiendo el modelo de Stonehouse de Plymouth, el primer hospital de pabellones construido en Europa en 1756-64. Las obras concluyeron en 1835, pero fue sufriendo un progresivo deterioro y manifestando su incapacidad para atender las necesidades de la creciente población bilbaína.

25 A.H.F.B. Municipal Bilbao. Bilbao Actas 0307 (1873-1874). 
En principio, el 16 de febrero de 1882 se aprobaba la reforma del Reglamento del hospital, que contemplaba, entre otras medidas, hacer extensiva la atención a los pobres de la villa. Pero, además, el Plan general incluía la creación de dos hospitales, de 200 camas cada uno. El problema residía en encontrar los terrenos óptimos y de tamaño considerable donde levantar los centros proyectados, cuando aún no había tenido lugar la anexión total de Abando. Las ofertas de terreno para levantar un nuevo hospital dieron como única alternativa a considerar la presentada por el alcalde Eduardo Victoria de Lecea y su madre, Sofía Arana, que ofrecían un solar de 4 hectáreas en jurisdicción de Abando. Los problemas legales y administrativos que acarrearía esta opción llevaron a desestimar la propuesta.

De manera que se optó por levantar un nuevo edificio de superficie más reducida en terrenos de la villa. Entretanto, ante la apurada situación por el elevado número de enfermos, se tomaron ciertas medidas que restringían las admisiones en el hospital, dándose prioridad a los vecinos frente a los forasteros (10.01.1889) ${ }^{26}$. En junio de 1889 se decidió la adquisición de $20.000 \mathrm{~m}^{2}$ en Solokoetxe para un nuevo hospital, el Ayuntamiento acordaba correr con todos los gastos que ocasionara la construcción del mismo y, por su parte, la Junta de Caridad anticiparía a la villa las cantidades que se invirtieran en dichas obras ${ }^{27}$. En 1892 las obras del edificio, que dispuso tan sólo de un pabellón de enfermedades venéreas, quedaron concluidas, cumpliendo su función como dependencia de Atxuri. También tuvieron dicho carácter los barracones de Larrínaga y de Mena, que habían sido habilitados de forma provisional.

Similares circunstancias confluyeron en torno a la habilitación de un nuevo cementerio, proyectado también en el Plan general de Obras Públicas ante el riesgo que para la salud pública suponían los camposantos de San Vicente de Abando y de Mallona, dada la escasez de espacio y las desfavorables condiciones higiénicas. En opinión de la comisión municipal de Gobernación (1887) que era refrendada por la Junta local de Sanidad $^{28}$, se consideraba poco recomendable la ampliación de éste último por ser costosa y sus terrenos poco aprovechables debido a su localiza-

26 A.H.F.B. Municipal Bilbao. Bilbao Actas 0356 (1889).

27 A.H.F.B. Municipal Bilbao. Bilbao Actas 0355 (1889).

28 M. Bilbao, «Arquitectura y arquitectos en el Cementerio de Bilbao», en www.bilbao.net, p. 3. Según detalla este autor, se estimaba que habría que albergar a 26.088 cadáveres y otorgando una superficie de enterramiento de dos metros, era necesario un terreno de extensión total de $52.176 \mathrm{~m}^{2}$. El principal obstáculo era encontrar un terreno con la su- 
ción en una pendiente y en las proximidades a la hondonada que comunicaba con la fábrica de gas. De acuerdo con la R.O. de 17 de febrero de 1888 se procedía a la búsqueda de terrenos para la construcción de un nuevo cementerio. En los meses siguientes fueron concretándose diversos proyectos para construir el nuevo cementerio en puntos tan dispares como Torre Urizar (Abando), Basurto (Abando), Mirabilla (Abando), Santo Domingo, isleta de Etxebarri o Ariz (Basauri). La comisión municipal de Fomento se decantó por el emplazamiento en Torre Urizar, bajo la ermita de San Adrián, propuesta que fue avalada por «entusiastas informes», ya que suponía disponer de $78.429 \mathrm{~m}^{2}$ y su orientación era adecuada. Pero finalmente fue desestimada por no hallarse a la distancia de la población que la ley exigía, como también lo fue definitivamente el proyecto de ampliación del cementerio de Mallona con terrenos de Eduardo Victoria de Lecea.

Ligado al arreglo sanitario propuesto en el Plan general de Obras Públicas, vino el propio de la beneficencia municipal, confiado a una comisión especial creada para dichos fines que resultó clave hasta que ésta obtuvo un carácter permanente en el seno de las comisiones municipales. Dicha comisión tuvo su oficina en la calle Hernani, en el barrio obrero de San Francisco. Hasta la fecha, a cargo de la beneficencia municipal, se hallaban la Casa de Misericordia y el Hospital ${ }^{29}$. Miembro de la Junta de Caridad de la Casa de Misericordia, Fernando L. Ibarra gestionó en 1883 la creación de dos instituciones benéficas: las Casas cuna, para atender a los hijos de trabajadores durante el horario laboral, siendo la primera en abrirse la de Urazurrutia ${ }^{30}$, y el Asilo de Huérfanos ${ }^{31}$, para protección y recogida de huérfanos menores de siete años, instituciones regidas por

perficie necesaria para albergar el número de cadáveres estimado y suficientemente alejado del centro urbano como requería la legislación vigente.

29 A.H.F.B. Municipal Bilbao. Bilbao Actas 0313 (1879-1880). En ciertos momentos de especial crudeza del invierno, contracción del mercado laboral o aumento de la pobreza en la villa, el Ayuntamiento contribuía a sostener un comedor económico, contando con la ayuda económica del vecindario.

${ }^{30}$ El proyecto de reforma contemplaba el establecimiento de tres salas-cuna en barrios trabajadores y periféricos, esto es, una en San Francisco, otra en la «aglomeración» AtxuriOllerías y otra en la correspondiente a Iturribide-Cristo-Tívoli.

31 C. E. Franquet, «El Asilo de Huérfanos de la Casilla», en Vida Vasca n. ${ }^{\circ} 22$ (1945), pp. 225-229. Dicho Asilo, tras la anexión de Abando en 1890, fue trasladado a la Casa Ayuntamiento de dicha anteiglesia en La Casilla, quedando al cuidado de las Hermanas de la Caridad de San Vicente de Paul. 
juntas de concejales y vecinos de la villa que habilitaron locales y pisos para el desempeño de dichas funciones. A éstos se sumaron una sala de convalecientes y parturientas y un asilo para transeúntes, al tiempo que se organizó la atención domiciliaria, con una distribución, más equitativa, de los distritos médicos.

En 1885, año crítico asociado a la epidemia de cólera, se propuso la formación de un padrón de pobres, cuyas bases se acordaban el 23 de noviembre ${ }^{32}$. Como puntualiza J. Gracia, en realidad este Padrón de pobres no es tal, sino un mero vecindario, puesto que sólo están inscritos los cabezas de familia ${ }^{33}$. Realizado por los alcaldes de barrio, el Padrón arrojaba la cifra de 4.525 personas, de manera que, según los censados, el porcentaje de las familias consideradas como pobres alcanzaba el $45 \%$ de las familias de Bilbao ${ }^{34}$. En opinión de dicho autor, el porcentaje de pobres bilbaínos, respecto a la población total, estaría muy cerca de las cifras estimadas para otras sociedades coetáneas, sirvan como base el 30\% de la población urbana británica o el 26\% de la población burgalesa. Dicho padrón había de servir de norma para la asistencia médico-farmacéutica gratuita, socorros de la beneficencia domiciliaria e ingreso en cualquier establecimiento benéfico. Asimismo, el elevado número de familias incluidas justificó la creación de dos nuevas plazas de médicos titulares.

Pocos meses después de su formación, la corporación municipal daba la voz de alarma ante la afluencia masiva de trabajadores a Bilbao en demanda de empleo, en torno al millar. De modo que se estudió la concesión de socorros extraordinarios para los más necesitados, que se verían favorecidos por la beneficencia municipal, sin la necesidad de cumplir el requisito del año de residencia y tras manifestar buena conducta. En consecuencia, a partir de esta fecha de 1886, se establecía la

32 A.H.F.B. Municipal Bilbao. Bilbao Tercera 0378/001.

33 A.H.F.B. Municipal Bilbao. Bilbao Tercera 0378/001. Relación por orden alfabético de los pobres del término municipal con derecho a asistencia médico-farmacéutica, en la que figura la referencia expresa de la calle, número y piso donde habitaban por distritos, así como también la edad, estado civil y profesión.

34 J. Gracia Cárcamo, «Aspirando a sobrevivir: Hogares y familias pobres en Bilbao a finales del siglo XIX», en L. Castells Arteche (ed.), El rumor de lo cotidiano. Estudios sobre el País Vasco contemporáneo, Universidad del País Vasco, Bilbao, 1999, pp. 121122. Ver también M. González Portilla (Ed.), Los orígenes de una metrópoli industrial..., op. cit., Vol. I, p. 314. 
asistencia municipal médico-farmacéutica ${ }^{35}$ o beneficencia domiciliaria en Bilbao, fecha tardía, según J. Gracia, si se tiene en cuenta que la Ley de Sanidad que preveía este tipo de acción benéfica estaba fechada en 1855 y que la ley que regulaba la Beneficencia Municipal databa de $1877^{36}$. Sin embargo, reconoce dicho autor que constituía un importante precedente del Estado de Bienestar, dado el vacío asistencial que existió hasta la época, luego remediado a comienzos del siglo XX con mecanismos de previsión social.

En 1889, se realizó una rectificación del Padrón mencionado, solicitaron su inclusión 1.200 familias, y se estableció un servicio farmacéutico libre para dicho colectivo (11.07.1889) ${ }^{37}$. Asimismo, una comisión especial, encabezada por el alcalde Celestino Ortiz de la Riva, gestionó con la Diputación la mejora de la beneficencia hospitalaria, dadas las malas condiciones de las Casas cuna y del Asilo de Huérfanos. Presidía entonces la Diputación vizcaína Pablo Alzola (18861890). A raíz del acuerdo establecido, la institución provincial pasaba a subvencionar la asistencia hospitalaria y financiaba las estancias de enfermos ajenos al municipio. Asimismo, se aprobaba la subvención de un $20 \%$ de las inversiones realizadas por los ayuntamientos en la compra de terrenos y en las obras de los hospitales que se construyesen en Bizkaia, dado que se había desechado la idea de construir un Hospital Provincial, por los beneficios de la descentralización en el ramo de los servicios públicos ${ }^{38}$.

\subsection{Las deficiencias del suministro de agua y del saneamiento}

Los aportes de agua de Uzkorta (1863), Abrisketa (1870) y La Alberca (1873) no habían solucionado el problema de abastecimiento, que

35 Además de la asistencia médica y farmacéutica gratuita, la beneficencia domiciliaria incluía socorros de lactancia y en ocasiones alimentos, constituyendo la partida más significativa dentro de la beneficencia municipal (Casa de Misericordia, Hospital, Casas cuna, Asilo de Huérfanos, Asilo de transeúntes, comedor económico).

36 J. Gracia Cárcamo, «Aspirando a sobrevivir...», op. cit., p. 130.

37 A.H.F.B. Municipal Bilbao. Bilbao Actas 0357 (1889).

38 P. Alzola, Discurso pronunciado por el Sr. Pablo de Alzola, presidente de la Diputación de Vizcaya en la sesión celebrada el 29 de diciembre de 1890, Imprenta Provincial, Bilbao, 1890. 
se estaba convirtiendo ciertamente en estructural ${ }^{39}$. Las deficiencias afectaban a los barrios obreros, pero también a la recién anexionada zona de Abando $^{40}$. En 1877 la comisión municipal de Fomento emitía un detallado informe de los suministros y las necesidades de la población, que concluía con el rechazo de la propuesta de traer agua de otros manantiales. Había que tomarla de la ría, pero dándole más presión al elevarla con el auxilio de máquinas, de ahí la conveniencia de construir un depósito en Miraflores y, a partir del mismo, surtir a las zonas anexionadas. A propuesta del alcalde Pablo Alzola, se encargó la elaboración de dicho proyecto a E. Hoffmeyer ${ }^{41}$.

En el mencionado informe, la comisión municipal había tomado como base para establecer las futuras necesidades de agua el aumento de la población bilbaína contemplado en el Plan de Ensanche ${ }^{42}$. Los cálculos de abastecimiento, 80 1./hab./día ${ }^{43}$, fueron realizados en base a una población estimada de 55.000 habitantes que, en 50 años, alcanzaría los 66.000, previsiones que, en breve, resultarían inservibles, dado el espectacular crecimiento de Bilbao. En 1887 Bilbao arrojaba ya la cifra de 50.772 habitantes, en 1920, cuando tan sólo se había consumado la anexión total de la anteiglesia de Abando, su población se elevaba a 112.819 habitantes.

39 A.H.F.B. Municipal Bilbao. Bilbao Tercera 0425/001. Informe de la comisión de aguas de Bilbao, presidida por el alcalde Felipe Uhagón (10.01.1877).

40 A.H.F.B. Municipal Bilbao. Bilbao Primera 0186/052. El 27.11.1878, vecinos propietarios de Abando transmitían a la corporación el lamentable estado en que se hallaba la parte poblada de la zona anexionada de Abando por la carencia absoluta de aguas potables para el consumo. Asimismo, manifestaban la falta de alumbrado público, que a la zona le correspondía.

${ }^{41}$ Dicho proyecto se encuentra recogido en el artículo «Mejoras urbanas de Bilbao», en Revista de Obras Públicas, n. ${ }^{\circ} 10$ (1880), pp. 109-112.

42 J. Cárcamo (ed.), Memoria del proyecto de Ensanche..., op. cit., p. 49. En dicha Memoria, sus autores calculaban el aumento de población «en la hipótesis de que subsista la misma ley de crecimiento que en los doce años comprendidos entre 1857 y 1869 , a pesar de que en un orden regular el desarrollo ha de ser más rápido». Dichos cálculos arrojaban la cifra de 62.423 almas para 1917 y de 70.543 para 1924 .

43 «Mejoras urbanas de Bilbao», en Revista de Obras Públicas, T. XXVIII, n. ${ }^{\circ} 10$ (1880), p. 109. Se estimaba en 80 1. la cantidad que a cada habitante había de asignarse diariamente, término medio entre los 90 1. que se habían calculado para Madrid en base a dicho concepto y los 70 1. a los que podían reducirse los de Bilbao, teniendo en cuenta que podían seguir utilizándose las aguas que se tomaban de la ría. 


\section{Tabla 2}

Evolución de la población de Bilbao 1860-1930

\begin{tabular}{lrrrrrrr}
\hline Municipio & 1860 & 1877 & 1887 & 1900 & 1910 & 1920 & 1930 \\
\hline Bilbao & 17.969 & 32.734 & 50.772 & 83.306 & 95.536 & 112.819 & 161.987 \\
Deusto & 1.899 & 2.323 & 2.972 & 4.142 & 5.777 & 7.911 & \\
Begoña & 4.535 & 1.867 & 2.662 & 5.802 & 7.279 & 11.097 & \\
Abando & 5.079 & 2.771 & 4.015 & & & & \\
\hline Total & 29.482 & 39.695 & 60.421 & 93.250 & 106.592 & 131.827 & 161.987
\end{tabular}

Fuente: M. González Portilla (Ed.), Los orígenes de una metrópoli industrial: La Ría de Bilbao, Fundación BBVA, Bilbao, 2001, Vol. I, p. 153.

De manera que el Ayuntamiento posterior, presidido por Marcelino Goicoechea (19.06.1879-4.03.1880), aprobaba el proyecto presentado por E. Hoffmeyer que proponía una nueva fuente de abastecimiento, el arroyo «Ventaco-erreca» (Arrigorriaga), y suplir las deficiencias durante el verano con agua de la ría. Al mismo tiempo, en noviembre de 1879, Ayuntamiento y Junta de permanente de la propiedad acordaban las bases para unificar el servicio de aguas con objeto de extenderlo a todo el término municipal ${ }^{44}$. En circular de 29 de diciembre se hacía pública la definitiva unificación del servicio ${ }^{45}$, el Ayuntamiento obtenía la exclusiva propiedad y todos los derechos de administración y gestión quedaban al cuidado de la municipalidad.

El 30 de julio de 1880 se sacaban a subasta las obras del proyecto de traída de aguas del arroyo «Ventaco-erreca» ${ }^{46}$, nuevo servicio que contaría con dos redes de agua: una potable, con las aguas de los manantiales que se habían ido captando, y otra no potable, procedente de la ría y elevada mediante la utilización de bombas, destinada a limpieza y usos industriales. Pero, las obras no concluyeron hasta 1886.

\footnotetext{
44 A.H.F.B. Municipal Bilbao. Bilbao Actas 0313 (1879-1880).

45 El Noticiero Bilbaíno, 1 de enero de 1880.

46 A.H.F.B. Municipal Bilbao. Bilbao Actas 0313 (1879-1889).
} 
Entretanto, proseguían las medidas para contener abusos ${ }^{47}$ y los bandos municipales de buen gobierno que advertían, al menos desde 1884, de los riesgos y peligros derivados de la mala calidad de las aguas ${ }^{48}$, contemplada la posibilidad de que la epidemia de cólera que se propagaba por Europa llegara a este territorio. Así fue a principios de otoño de 1885, cuyos efectos se prolongaron hasta concluir el año. La escasa incidencia que tuvo en Bilbao, comparativamente con las localidades mineras e industriales de la Ría, refleja la eficacia de las medidas preventivas adoptadas por la corporación municipal meses antes de manifestarse la enfermedad, corporación presidida por Vicente Urigüen (1885-1887) que iniciaba su gestión con el presagio del cólera ${ }^{49}$. Las medidas de urgencia habían funcionado, pero aún estaba pendiente la modernización sanitaria, del abastecimiento de agua, limpieza y saneamiento, resurgiendo la polémica de buscar terrenos para un nuevo hospital, un nuevo cementerio, una nueva alhóndiga municipal, en unos años que coincidían con la fase de mayor impacto de la mortalidad en la Ría de Bilbao. El principal responsable del incremento de la tasa bruta de mortalidad en dicha área en el período de 1877-1890 fue el grupo de enfermedades transmitidas por aire (70\%), seguido de las enfermedades relacionadas con la alimentación y las aguas en mal estado $(13,49 \%)$, como señala $\mathrm{M}$. Arbaiza ${ }^{50}$, quien puntualiza también que, hasta 1890 , en Bilbao y en la zona minera se experimentó un primer aumento de las infecciones transmitidas por agua y alimentos.

En 1886 entraban en funcionamiento una central de depuración y bombeo en la isla de San Cristóbal, que elevaba, mediante bombas, las aguas al depósito de Miraflores, todo ello según proyecto de E. Hoffme-

47 A.H.F.B. Municipal Bilbao. Bilbao Tercera 0425/001. Comisión de aguas de Bilbao, firmado el alcalde Manuel Lecanda (17.05.1881). A fin de corregir los abusos cometidos, tales como el ensanchamiento del diámetro de las llaves y su apertura constante, que producían un «exorbitante e innecesario consumo de agua», dicha comisión decidía proceder a reconocimientos y visitas domiciliarias.

48 P. A. Novo, «Agua potable en los hogares: ¿una innovación? El abastecimiento y consumo de agua en los municipios de la Ría de Bilbao, 1850-1930», en Seminario Salud y Ciudades en España 1880-1940, Barcelona, 2010 (www.proyectonisal.org/index. php?option=com_docman...es).

${ }_{49}$ M. González Portilla (Ed.), Los orígenes de una metrópoli industrial..., op . cit., Vol. I, pp. 289-290 y S. Serrano, «Urigüen Ansotegui, Vicente», en J. Agirreazkuenaga (Dir.), Bilbao desde sus alcaldes. Diccionario biográfico de los alcaldes de Bilbao y gestión municipal en tiempos de revolución liberal..., op. cit., pp. 527-537.

50 M. Arbaiza, «La transición sanitaria en Vizcaya», en M. González Portilla y K. Zarraga Sangroniz (Eds.), Hospital de Bilbao y transición sanitaria..., op. cit., pp. 128-129. 
yer. La instalación de la isla de San Cristóbal sirvió a su vez como central de producción de energía eléctrica para la primera red de alumbrado público de Bilbao. Las mejoras vendrían también con la aprobación del Plan distributivo de fuentes. Elaborado igualmente por el anterior (1882), suponía dotar de los dos tipos de suministro de agua a fuentes ya existentes y construir otras de nueva planta en los barrios de Mirabilla y San Francisco, en Abando y en la zona anexionada de Begoña (Tívoli).

Sin embargo, apenas un mes después de iniciarse el nuevo servicio, se registraban las malas condiciones del arroyo Iturrigorri. En consecuencia, se acordaba el nombramiento de una Comisión especial de Saneamiento (1.07.1886) y se aprobaba la moción del alcalde Vicente Urigüen, sobre traída de agua de nuevos manantiales (aguas de Larrumbe en Arrigorriaga). Las actuaciones emprendidas por la corporación municipal evidenciaban claramente que, al agua, estaba unido el problema del saneamiento, entre las mismas, la puesta en marcha del proyecto de alcantarillado del arroyo Elguera a su paso por Abando, objeto de vertidos urbanos y labores de limpieza, así como la creación en 1885 de una Junta especial para limpieza de la ría.

\subsection{Los desequilibrios del Ensanche}

Las investigaciones de J. M. ${ }^{a}$ Beascoechea, sobre la base del Padrón de Fincas Urbanas del municipio de Bilbao realizado en 1892, revelan que quince años después de la puesta en marcha del Plan de Ensanche se habían levantado en el mismo 294 construcciones, menos del 17\% del total de la ciudad ${ }^{51}$. Pero incluso, como apunta dicho autor, la mencionada cifra debe ser matizada, «ya que al menos el 10\% eran de uso industrial exclusivo (almacenes, talleres, fábricas...) y una parte importante - sobre todo en la zona de las calles Estación (Navarra), Amistad y Sierra (Buenos Aires) - se levantaron antes de $1876 »^{52}$. Por otro parte, se estaban configurando en el Ensanche dos situaciones bien diferenciadas al norte y al sur de su arteria principal, la Gran Vía, que salían a relucir al realizar la

51 J. M. ${ }^{a}$ Beascoechea Gangoiti, «La Construcción urbana del nuevo hospital...», op. cit., p. 167.

52 González Portilla, M. (Dir.) Bilbao en la formación del País Vasco Contemporáneo (Economía, población y ciudad), Fundación BBV, Bilbao, 1995, p. 379. 
valoración media de renta por vivienda individual ${ }^{53}$. En el sector sur, tomando como base la calle Fernández del Campo, comenzaba a manifestarse la formación de bolsas de viviendas de baja calidad, acompañadas de elementos urbanos que rebajaban la categoría arquitectónica y social de la zona (cocheras del tranvía, talleres, almacenes o la casa cuartel de la Guardia Civil). En este entorno se apreciaban los valores medios de rentas prácticamente más bajos de la ciudad, entre 225 y 350 pts., tan sólo inferiores en los barrios marginales de Bilbao La Vieja, Olabeaga y Zorroza.

En cambio, la calle Estación se distinguía por el nivel de precios de sus viviendas, 1.605 pts. de valor medio, por encima de la Gran Vía (1.237 pts.). Es en este sector que articula las comunicaciones y los tres espacios funcionales claves de la ciudad - casco viejo, Ensanche y puerto-, donde se van a localizar las actuaciones municipales en esta fase inicial de modernización. Se concluye la construcción la Alhóndiga Principal en 1887, proyectada en el Plan General de Obras Públicas de Eduardo Victoria de Lecea y levantada en terrenos propiedad de los hermanos Zabálburu, junto a las Escuelas de Berástegui (actuales Juzgados). Su emplazamiento no podía ser más ventajoso, cerca de los muelles de la ría y de los enlaces ferroviarios que daban servicio al puerto.

Esta nueva alhóndiga respondía a la necesidad de contar con un depósito general de almacenamiento y conservación de alimentos y bebidas, acorde con el aumento de la población y sus necesidades de abastecimiento $^{54}$. Dichas funciones ya no las podían desempeñar ni el antiguo Peso y Alhóndiga General del Portal de Zamudio ${ }^{55}$, ni los almacenes o depósitos de las mercancías sujetas a impuesto municipal que el ayuntamiento fue incorporando (calle Ronda, Jardines y Somera).

53 Ibidem., p. 387.

${ }^{54}$ La documentación hallada en el Archivo Histórico de la Diputación de Bizkaia permite confirmar la existencia de una antigua alhóndiga municipal desde el siglo XVI al XVIII, destinada a depósito de trigo y ubicada en los bajos de la Casa Consistorial, radicaba junto a la iglesia de San Antón. Ver A.H.F.B. Judicial. Corregimiento JCR0448/053 (1565), JCR0152/036 (1581), JCR0152/037 (1581), JCR0152/064 (1581), JCR1408/073 (1588), JCR1158/023 (1675), JCR1646/022 (1676), JCR1108/068 (1726) y JCR0959/027 (1776). Los antecedentes históricos de esta institución se pueden seguir en la obra de Basas, M. Breve Historia de la Alhóndiga Municipal de Bilbao, Gráficas Ellacuria, Bilbao, 1970.

55 A.H.F.B. Municipal Bilbao. Bilbao Cuarta 0131/004. Construida en 1807-1809 en los terrenos de la antigua cárcel, tenía una superficie de $456 \mathrm{~m}^{2}$. El edificio se destinaba en su mayor parte a alhóndiga, otra de $416,40 \mathrm{~m}^{2}$ era arrendada por el ayuntamiento (calle Somera y Ronda). 
Junto a la nueva alhóndiga, reforzando la orientación portuaria e industrial que estaba tomando este sector de la ribera de Abando, se ubicaría la nueva aduana, cuyas obras daban comienzo en $1890{ }^{56}$. En el debate que se generó años antes en torno su ubicación, planteado por la Junta de Obras del Puerto, se dejaban traslucir los recelos ante el «salto» de Bilbao a la otra orilla. Las diferencias surgieron a la hora de decidir su emplazamiento, que enfrentó a los defensores del casco antiguo y a los partidarios de su localización externa en Uribitarte, área portuaria en expansión. La aduana, símbolo de la ciudad portuaria y mercantil, fue reflejo de la pugna entre tradición y modernidad que se mantenía en los ámbitos intelectuales y entre las élites dirigentes.

De manera que la alhóndiga, la aduana, las escuelas de Berástegui y el mercado cubierto eran los únicos edificios públicos que, en torno a 1890, se habían levantado en el Ensanche, mientras que el emplazamiento designado para el nuevo Teatro (1890) y la Casa Consistorial (1892), obras proyectadas durante la Alcaldía de Eduardo Victoria de Lecea, venía a confirmar la centralidad aún manifiesta del casco antiguo.

En cuanto a la urbanización de calidad del Campo Volantín y Huertas de la Villa, surgía como prolongación del casco antiguo, donde se fueron levantando chalés y villas ajardinadas de la alta burguesía urbana de valores muy superiores a las mejores casas de pisos de la ciudad nueva (Gran Vía y Estación). Sin embargo, en sus aledaños hicieron su aparición grupos de viviendas de bajo nivel. En esta zona de Tívoli-Castaños-Cristo, limítrofe con la anteiglesia de Begoña, los valores medios de renta en viviendas individuales se situaban incluso por debajo de San Francisco (326 pts. $)^{57}$. En concreto, en Tívoli se proponía en 1878 levantar el nuevo matadero de la ciudad, así como el edificio destinado a servicio de venta de carnes, conocido como el Rastro, por localizarse ambos en pleno casco urbano antiguo (actual calle Banco de España). La corporación municipal ya en 1858 reconocía la antigüedad, mala situación y deterioro del matadero, y veía la necesidad de construir uno nuevo en las afueras de la villa, pero se fue demorando el proyecto. Por R.O. de 22 de agosto de 1879 el Ministerio de la Gobernación concedía al Ayuntamiento de Bilbao auto-

${ }^{56}$ La aduana se había establecido en 1841 en el antiguo convento de Agustinas de Santa María, en la trasera de la iglesia de San Nicolás.

57 M. González Portilla (Dir.), Bilbao en la formación del País Vasco..., op. cit., p. 387. 
rización para enajenar los edificios de matadero y carnicería ${ }^{58}$. Tres años más tarde, se inauguraba en Tívoli el nuevo matadero ${ }^{59}$, que fue objeto de sucesivas ampliaciones a fin de dotarlo de un eficaz servicio ${ }^{60}$.

En sus inmediaciones, en el barrio del Cristo, las viviendas compartían suelo con ciertos usos industriales y con la fábrica de gas, radicada en la barranca de Sendeja, cuyas instalaciones entraron en funcionamiento en 1849 a cargo de la Société pour l'éclairage au gaz de la Ville de Bilbao (Lyon). La fábrica, destinada a la iluminación pública y adquirida por el Ayuntamiento por R.O. de 6 de enero de 1886, contribuyó a degradar este enclave dadas las emanaciones de la misma. Del estudio del establecimiento y la expansión del servicio de gas en Bilbao se ha ocupado A. Fernández ${ }^{61}$, que lo considera, junto con el agua y la electricidad, un elemento clave para «medir» la modernidad y el progreso de las ciudades.

Realizados los primeros ensayos de alumbrado público eléctrico, la corporación municipal comenzó a plantearse la utilización de la central elevadora de agua de San Cristóbal, que permitió la electrificación de la Plaza Nueva, el Arenal, Ribera, puentes de la ría y calle Estación ${ }^{62}$, arteria central urbana. Ante el gasto que suponían ambos servicios, la electricidad pasó a la iniciativa particular, disfrutando pronto de la misma el casco viejo y el Ensanche. En 1889 era aprobado definitivamente el proyecto de instalación del alumbrado eléctrico en calles, paseos y plazas de la villa, se procedió a la reforma de las máquinas de San Cristóbal para mejora del alumbrado eléctrico y, un año después dio comienzo la instalación de tomas en las viviendas de la villa (1890).

58 A.H.F.B. Municipal Bilbao. Bilbao Cuarta 0118/023. Expediente que se eleva al Ministerio de la Gobernación.

59 A.H.F.B. Municipal Bilbao. Bilbao Cuarta 0131/004.

60 A.H.F.B. Municipal Bilbao. Bilbao Cuarta 0039/013 y Bilbao Tercera 0465/031.

61 A. Fernández, Un progressisme urbain en Espagne. Eau, gaz, électricité à Bilbao et dans les villes cantabriques, 1840-1930, Presses Universitaires de Bordeaux, Pessac, 2009. Indudable aportación al conocimiento de la modernización de las ciudades españolas, en dicha obra el autor analiza la instalación y gestión de los servicios de agua, gas y electricidad en Bilbao, San Sebastián y Santander en las fechas señaladas. Establece una relación directa entre crecimiento demográfico y económico y el aumento de la demanda urbana. La corporación municipal bilbaína asumió dicha demanda que, a partir de 1880, se interpretó como una necesidad colectiva, que impulsó a través de la ampliación y mejora de las redes de abastecimiento.

${ }^{62}$ M. González Portilla, Bilbao en la formación..., op. cit., pp. 457-458. 


\subsection{Las estrecheces de la hacienda local}

La tónica general durante el período de 1876 a 1890 fue la falta de recursos para llevar a cabo las obras proyectadas y amortizar los préstamos emitidos, algunos de los mismos, auténtico freno para la administración, por haber sido emitidos en el corto plazo de 12 o 15 años. De ahí que en 1882 Fernando L. Ibarra planteara la unificación de la deuda, rebajar el tipo de interés y arbitrar recursos para obras de gran envergadura. De hecho, se emitió un empréstito de 5 millones de pts. al 4\%, amortizable en un plazo que no excediera los 30 años, pero la comisión de Hacienda desaconsejó entonces la unificación por las dificultades del mercado, quedando desde aquella fecha como un empréstito más. En 1886 se acordaba la emisión de uno nuevo para atender los gastos originados por la adquisición de la fábrica de gas y se ampliaba el correspondiente a nuevas construcciones. La operación de unificación se demoró hasta 1896.

Otros recursos fueron el recargo en los artículos de consumo, no sin las quejas de vecinos y comerciantes; la ampliación y creación de nuevos impuestos, entre los mismos fue especialmente contestado el impuesto de espectáculos públicos, que hubo de ser modificado, y el de rótulos, que comerciantes e industriales puntualmente consiguieron revocarlo $(1880)^{63}$; la venta de propiedades municipales, como fueron los solares de la isla de Uribitarte o la antigua Casa de la Misericordia, y finalmente la derrama sobre la propiedad (1889). El cobro de las cuotas correspondientes a la derrama no fue fácil, dada la oposición de los propietarios, que propusieron para el futuro la incorporación de industriales y comerciantes en la proporción debida a las derramas. Por su parte, la Junta de la Propiedad tropezó con serias dificultades para obtener los datos en base a los cuales practicar el reparto.

A finales de la década de los años 80, bajo la Alcaldía de Celestino Ortiz de la Riva ${ }^{64}$, ante el estado precario de la hacienda municipal fue sometido a estudio el aumento disparado de los presupuestos. Se valoró su evolución en el trascurso de los últimos 30 años, de forma comparativa con los de la Diputación. El incremento experimentado en los presupuestos municipales hacía que éstos se elevaran a 5 millones de pts. y, en con-

63 A.H.F.B. Municipal Bilbao. Bilbao Actas 0313 (1879-1880).

${ }^{64}$ S. Serrano, «Ortiz de la Riva Allendesalazar, Celestino», en J. Agirreazkuenaga (Dir.), Bilbao desde sus alcaldes. Diccionario Biográfico de los alcaldes de Bilbao y gestión municipal en tiempos de revolución liberal..., op. cit., pp. 546-547. 
secuencia, excedían a los provinciales, incremento derivado del Ensanche, obras públicas y notables gastos de personal. Ello suscitó la propuesta de reformar el sistema de tributación y su sustitución por la contribución directa. Las comisiones de Hacienda y de Estadística se encargaron de elaborar el procedimiento y las reglas para la formación de un catastro (1888).

Precisamente en este sentido ya se había manifestado la Diputación con anterioridad, en un intento de que las cargas generales se repartieran en proporción a la riqueza de todos los vizcaínos, e incluso fue aprobado en 1884 un reglamento para la imposición y cobranza de la contribución sobre inmuebles, cultivo y ganadería, industria y comercio ${ }^{65}$. Dos años después, una Comisión especial de Estadística, presidida por Pablo Alzola, comenzó los trabajos preparatorios que culminarían en 1890 con un informe sobre las bases que habían de regir en la formación de una estadística territorial. Sobre estas bases, se formó una Estadística territorial, de ámbito provincial (1893), y a continuación se emprendió la realización de una Matrícula de Industria y Comercio, organizada por localidades, según la base de su población (1894-1895). Como apunta J. M. ${ }^{a}$ Beascoechea, «al parecer debido a las ventajosas condiciones alcanzadas en la renovación del Concierto Económico en 1894, todo el trabajo no llegó a concretarse en una Contribución Territorial efectiva, manteniéndose incluido convencionalmente este concepto entre las partidas del Cupo» ${ }^{66}$.

Por último, la liquidación de las deudas de las anteiglesias de Abando y Begoña fue motivo de unas intensas y prolongadas conversaciones entre las partes, en las que participó Manuel Lecanda, entonces teniente de alcalde y presidente de la comisión liquidadora (1883). Más adelante, el análisis de la hacienda municipal de Abando durante el período de 1878 a 1890 demostró la existencia de pagos indebidos, excesivos y duplicados, informe que fue remitido a la institución provincial para que se depurasen responsabilidades. El acuerdo con los acreedores de dicha anteiglesia se formalizó en 1891-1892 y se resolvió el pago de sus créditos con títulos de un nuevo empréstito.

65 Reglamento para la imposición y cobranza de la Contribución sobre Inmuebles, Cultivo y Ganadería, Industria y Comercio, Bilbao, 1885.

${ }_{66}$ M. González Portilla (Dir.), Bilbao en la formación del País Vasco..., op. cit., pp. 371-372. 


\section{Retos y debates en la ciudad del progreso (1890-1920)}

Bilbao era ya al finalizar el siglo XIX un centro industrial y financiero, con un puerto de referencia a escala nacional, una extensa red de infraestructuras ferroviarias de carácter intra y extrarregional y un potencial demográfico que le convertían en la capital del norte de España. Sin embargo, las elevadas tasas de crecimiento de la población, difíciles de prever, la propia problemática que arrastraba la ciudad tradicional, a falta de suelo para su regeneración, la magnitud de los efectos derivados del proceso de industrialización en marcha, así como los limitados recursos de la hacienda local ralentizaron en una fase inicial la ampliación y modernización de los equipamientos y servicios públicos, sin conseguir avanzar al ritmo que el crecimiento económico y demográfico imponían.

No obstante, a partir de la segunda mitad de los años 90 cobró vitalidad el impulso para poner en marcha múltiples proyectos que fueron culminando durante el primer decenio del siglo Xx. La gran obra, la red de saneamiento y evacuación de vertidos se daba por concluida en 1903 mitigando los problemas de limpieza, higiene y salud pública debido al consumo generalizado de agua de la ría. A ésta se sumaron la construcción del nuevo Hospital de Basurto (1908), dada la disponibilidad de terrenos tras la anexión de Abando, el cementerio (1902), que forzosamente hubo de salir de la ciudad, y la alhóndiga central (1909), gran depósito municipal que se hacía un hueco en el Ensanche. Aunque en el camino hubo también desaciertos, gastos inútiles e incertidumbres, que generaron un vaivén de traslados, reubicaciones y acondicionamientos de servicios; el hospital de Solokoetxe (1893) nació ya caduco, con escasa vida la alhóndiga de Barroeta Adamar y los parques de bomberos fueron «danzando» hasta su final ubicación. E incluso se produjeron fracasos, los suministros de agua potable, «siempre el agua», como la opinión pública se manifestaba para hacer referencia a un tema pendiente de una solución definitiva.

Fue, en todo caso, un proceso costoso. Por un lado, a causa de los elevados gastos que las múltiples obras generaron, llegaron incluso a comprometer los presupuestos municipales, difíciles de sostener con los recursos legales que autorizaba la Diputación, máxima autoridad en materia fiscal. Por otro, porque suscitó fuertes y complejos debates dentro y fuera del consistorio municipal, debates en los que se hallaban implícitos los efectos sociales del llamado «progreso» de Bilbao.

La precariedad de la hacienda municipal, derivada fundamentalmente del incremento notable de los gastos de personal y obras públi- 
cas, promovió un constante debate sobre la reforma del sistema de tributación, hasta el punto de que se planteó de nuevo la posibilidad de la contribución directa sobre la propiedad. La alternativa salía a la palestra en toda discusión sobre la captación de nuevos ingresos, debate que incluía también la reclamación de mayor autonomía para los poderes locales en la fijación de impuestos frente a la administración provincial, de cuya aprobación dependían. El empréstito y los recargos sobre los consumos fueron los recursos más habituales, de ahí las constantes quejas del vecindario ${ }^{67}$, que acusaba al Ayuntamiento de «abrir demasiado la mano» a la beneficencia y tener exceso de empleados ${ }^{68}$, en torno al millar en el cambio de siglo. Fechas en que, para contener el déficit, la Diputación autorizó cobrar una cuota sobre la Contribución Territorial e Industrial.

Un progreso que también había conducido a una nueva pluralidad en el Ayuntamiento bilbaíno desde los comicios de 1891, con concejales socialistas entre los electos, y a partir de 1899 con la entrada de los nacionalistas en el consistorio. No obstante, hasta 1917 los alcaldes continuaron siendo de real nombramiento, lo que permitió a los monárquicos, conservadores y liberales, acceder a la Alcaldía, a pesar de no ser más que una de las minorías que conformaban el Ayuntamiento ${ }^{69}$. La representación de este grupo dentro de la administración municipal fue decreciendo frente al ascenso de socialistas y nacionalistas, de ahí que cierto sector de sus dirigentes moderara sus postulados fundacionales para propiciar políticas de mayor consenso. Asimismo, la política de la conjunción de republicanos y socialistas les permitió, a partir de 1906-1907, una creciente influencia en el Ayuntamiento. Es obvio que estos nuevos integrantes del Ayuntamiento trasladaron al consistorio las reivindicaciones de sus votantes, lo que generó la incorporación de nuevos debates que comprometían a un amplio colectivo social, algunos de los mismos dejaban traslucir viejos problemas, pero eran abordados desde dispares perspectivas sociales. Esta dinámica, sin em-

67 Como también mostró una fuerte oposición al repartimiento general. Miguel Unamuno recordaba la protesta aplastante ante el practicado en 1891: «Los que no protestaron con la palabra lo hicieron con su silencio y su tácita negativa a auxiliar al municipio», en J. A. Ereño y A. Isasi, La cuestión del Ensanche de Bilbao. Miguel de Unamuno y Jugo. Pablo Alzola y Minondo, Ayuntamiento de Bilbao, Bilbao, 2000, p. 182.

${ }_{68}$ El Noticiero Bilbaíno, 6 de abril y 18 de mayo de 1899.

69 J. Agirreazkuenaga (Dir.), Bilbao desde sus alcaldes. Diccionario biográfico de los alcaldes de Bilbao en tiempos de revolución democrática y social Vol. II: 1902-1937, Ayuntamiento de Bilbao, Bilbao, 2003, p. 31. 
bargo, tuvo en ocasiones como contrapartida la paralización en la toma de decisiones y, en consecuencia, de las actuaciones a emprender.

Tabla 3

Gastos del Ayuntamiento de Bilbao 1878-1899 (pts.)

\begin{tabular}{lrrr}
\hline \multicolumn{1}{c}{ Gastos } & \multicolumn{1}{c}{1878} & $1893-1894$ & $1898-1899$ \\
\hline Personal administrativo & 183.890 & 1.296 .805 & 1.376 .852 \\
Policía, bomberos & 152.292 & 278.431 & 316.237 \\
Instrucción y cultura & 68.796 & 208.461 & 316.302 \\
Beneficencia y asistencia social & 44.225 & 159.112 & 197.542 \\
Obras públicas & 901.192 & 1.206 .601 & 3.144 .559 \\
Cárceles & 2.365 & 3.250 & 8.699 \\
Pensiones & 9.040 & 12.580 & 15.697 \\
Deuda y amortizaciones & 425.454 & 6.752 .592 & 1.601 .097 \\
Imprevistos & 30.000 & 25.000 & 20.000 \\
\hline Total & 1.817 .254 & 9.942 .832 & 6.996 .985 \\
\hline
\end{tabular}

Fuente: E. Alonso, «Los presupuestos municipales 1800-1997», en J. Agirreazkuenaga y S. Serrano, Viaje al poder en el ayuntamiento de Bilbao 1799-1999, Ayuntamiento de Bilbao, Bilbao, 1999, pp. 172-173.

\section{Tabla 4}

Composición de los ayuntamientos 1895-1914

\begin{tabular}{lcrrrrrrrr}
\hline \multicolumn{1}{c}{ Afiliación } & 1895 & 1897 & 1899 & 1901 & 1903 & 1906 & 1910 & 1912 & 1914 \\
\hline Republicanos & 12 & 4 & & & 12 & 13 & 12 & 10 & 12 \\
Nacionalistas vascos & & & 5 & 11 & 13 & 10 & 13 & 14 & 16 \\
Socialistas & 1 & 4 & 5 & 8 & 11 & 10 & 7 & 8 & 7 \\
Liberales (coalición) & 5 & 17 & 21 & 18 & 5 & 1 & 2 & 4 & 2 \\
Conservadores & & & & & & & 1 & 3 & 2 \\
Carlistas-Jaimistas & 15 & 10 & 3 & & & 7 & 5 & 1 & 2 \\
Demócratas & & & & & 1 & & & & \\
Posibilistas & 1 & 1 & & & & & & & \\
Independientes & & & 2 & 1 & & & & & \\
\hline
\end{tabular}

Fuente: Elaboración propia a partir de J. Agirreazkuenaga (Dir), Bilbao desde sus alcaldes. Vol I: 1836-1901 y Vol. II: 1902-1937. 
La expansión de la ciudad generó una intensa actividad constructiva que, desde su cargo como Arquitecto Jefe de Construcciones Civiles, asumió Ricardo Bastida, quien diseñó nuevos edificios públicos y reformó aquellos que pasaban a desempeñar otros usos. Se había incorporado al Ayuntamiento de Bilbao en 1903, en calidad de ayudante, dos años después firmaba ya como arquitecto municipal y en 1907 ascendía a la dirección mencionada. Desempeñó dichas funciones hasta 1927, si bien continuó vinculado como Jefe Consultor Técnico de Servicios Municipales hasta su muerte ${ }^{70}$. Figura, la del arquitecto, que era considerada entonces como el «porta-estandarte de todo progreso», «el capitán de la sociedad» ${ }^{71}$, en palabras de Federico Ugalde, arquitecto bilbaíno encargado de la ponencia inaugural del IV Congreso Nacional de Arquitectos, celebrado en Bilbao en 1907.

\subsection{Los retos, educación y salud pública}

Bilbao alcanzaba en 1900 una tasa de alfabetización de la población mayor de 9 años del 76,8\% que, sumada a la de los semianalfabetos, $2,5 \%$, suponía un elevado $79,5 \%$, por lo que estaríamos hablando de que se había alcanzado la alfabetización universal ${ }^{72}$. Había sido posible por las inversiones realizadas. La enseñanza pública había comenzado a disponer de edificios y locales propios, nuevas escuelas municipales que se construyeron en el casco viejo y en los barrios y extrarradios de la ciudad ${ }^{73}$. En 1894 de las 39 escuelas públicas existentes en Bilbao, 34 eran municipales (una de enseñanza superior, 32 de enseñanza elemental completa y 6 de adultos), tres de éstas se habían construido dicho año en el casco viejo. Las privadas ascendían a la cifra de 55: 20 superiores, 31 elementales completas y 4 de adultos. Desde el punto de vista de la titularidad, 22 de las escuelas municipales se ubicaban en locales propios,

70 J.R. Foraster, M. ${ }^{\text {a }}$ E. Bastida y G. Pérez de las Peña, Ricardo de Bastida, arquitecto, Colegio Oficial de Arquitectos Vasco Navarro, Bilbao, 2002.

71 IV Congreso Nacional de Arquitectos, Libro del Congreso, Imprenta y encuadernación de la Casa de Misericordia, Bilbao, 1907, p. 49.

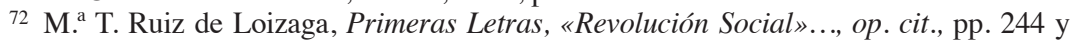
ss. Desagregados los datos, la tasa de hombres suponía un $87,9 \%$ y la de mujeres un $72,2 \%$, tasas que, en el conjunto de Bizkaia, se reducían a 74,2\% y un 57,6\% respectivamente, de hecho el territorio vizcaíno no alcanzaría la alfabetización universal hasta 1920 (80,4\%).

73 Ibidem., pp. 171 y ss. 
repartidos en siete edificios. En adelante, se construyeron tres escuelas en el casco viejo, un edificio para escuelas en el barrio de Ibaizabal en 1897, otro en el Ensanche (calle Fernández del Campo) en 1898, escuelas en Olabeaga en 1904 y, un año después, dos nuevas en Castrexana y el primer grupo escolar, las «Escuelas de Cervantes», con aulas destinadas a la docencia directa y otras instalaciones educativas necesarias para la formación. A éste último grupo se sumarían los de Múgica, Indautxu e Iturribide (1915-1917), proyectos del arquitecto municipal Ricardo Bastida.

Asimismo, iniciaba también sus cursos la Escuela de Ingenieros Industriales $(1899)^{74}$, destinada a la formación de buena parte del empresariado vizcaíno, capital humano que constituyó un factor clave del desarrollo económico de la provincia. Las reformas de los hospitales de Atxuri y de Solokoetxe, a cargo de Ricardo Bastida, sirvieron para instalar la Escuela de Artes y Oficios y Capataces (1910-1912) y la Escuela Normal de Maestras (1910), respectivamente.

El debate sanitario generado a partir de 1890 discurrió en torno a tres cuestiones: la construcción de un hospital de mayores dimensiones que resolviera los problemas asistenciales de Bilbao, el amortiguamiento de la mortalidad infantil y la reforma de los servicios médicos municipales. Respecto a la primera cuestión, la anexión de Abando en 1890, cuando aún no habían comenzado las obras de construcción del hospital de Solokoetxe, hubiera posibilitado la captación de terrenos y la elaboración de un nuevo proyecto. Máxime teniendo en cuenta que el centro de Solokoetxe nacería ya caduco, debido a los diversos brotes epidémicos y al excesivo aumento de mujeres con enfermedades venéreas. No fue así, de modo que, al año de la apertura, la Junta de Sanidad manifestaba su insuficiencia e incluso las dificultades del suministro de agua (3.04.1895).

Una comisión, integrada por miembros de la Diputación, el Ayuntamiento y la Junta de Caridad del Hospital, se reunía y sentaba las bases del convenio para la construcción de un nuevo establecimiento, contando con la subvención de la Diputación de un 20\% del capital invertido

${ }^{74}$ En 1894 el concejal Gaspar Leguina presentaba su moción para el establecimiento de dicho centro, basándose en el modelo de la escuela existente en Barcelona. A principios de 1897 intervenía directamente el alcalde Joaquín Moreno Goñi en las gestiones practicadas en Madrid. Por R. O. de 2 de abril de 1897 se autorizaba el establecimiento de la Escuela, a expensas de la Diputación y el Ayuntamiento. Ubicada en el frontón de Abando, sus cursos daban comienzo en otoño de 1899. 
de los fondos municipales para el coste de las obras ${ }^{75}$. Se optó por su localización entorno a la Torre de Basurto, en terrenos ya anexionados de Abando. Además de los benefactores, Diputación y Ayuntamiento aportaron a la Junta de Caridad 1.500.000 pts., fruto de la tasación del hospital de Atxuri. Enrique Epalza, arquitecto municipal, diseñó el nuevo centro, basándose en el moderno hospital de Eppendorf en Hamburgo. Desde el inicio de las obras en 1898 hasta su inauguración diez años después, fueron habilitadas diversas dependencias sanitarias, a las que se sumaron también la Casa de Socorro y Laboratorio municipal, ubicados en San Vicente.

La alarmante mortalidad de niños de corta edad ${ }^{76}$ suscitó un amplio debate, al tiempo que una comisión especial, integrada por los cinco presidentes de las comisiones permanentes del Ayuntamiento, buscaba soluciones atendiendo a los diversos factores causantes de la misma (1894). Se había tomado plena conciencia de la realidad, pero la dificultad estribaba en ejecutar un plan que se proponía la construcción de un hospital infantil, cuando se hallaba ya en marcha el nuevo de Basurto, y ligado a aquel, la búsqueda de nuevos suministros de agua, dejar de utilizar la procedente de la ría y la construcción de viviendas económicas. No obstante, en 1895 se comenzaba a suministrar el suero antidiftérico y, dos años después, daba comienzo la vacunación para la infancia, se establecía un laboratorio para examen y reconocimiento de la leche de nodrizas de beneficencia domiciliaria y se iniciaba la publicación del Boletín Sanitario Estadístico Municipal.

Completaron la red las nuevas instalaciones de la Casa Cuna de San Antonio (1912) y Casa de Socorro (1914-1916), localizadas en Urazurrutia y obra del arquitecto municipal Ricardo Bastida, como también lo fueron el Centro de desinfección municipal (1916) y los baños públicos de Recacoeche (1916). Desde 1884 había existido un servicio, establecido en la estación de Abando, para la desinfección de las mercancías

75 J. M. a Beascoechea, «La construcción del nuevo hospital...», op. cit., p. 199.

76 M. González Portilla, Los orígenes de una metrópoli industrial..., op. cit., Vol. I, pp. 369-370. El tema ha sido ampliamente desarrollado por A. Pareja en Inmigración y condiciones de vida en la villa de Bilbao, 1895-1935, Tesis Doctoral, Universidad del País Vasco, Bilbao, 1997. El diagnóstico es alarmante en ambos, que establecen un coeficiente de mortalidad infantil (niños menores de 1 año) en Bilbao para el período de 1870 a 1907 de entre 160 y 200 por mil. La mortalidad juvenil (niños de 1 a 4 años) mantuvo cifras que oscilaban entre los 260 y los 320 por mil entre 1896 y 1896, siendo ya muy inferiores las correspondientes a niños de 5 a 9 años. 
procedentes de zonas de riesgo de epidemias, tras su acondicionamiento posterior en Mena y en Zabalbide, se construyó el mencionado centro de Zancoeta.

En cuanto al cementerio, se alcanzó en 1891 el acuerdo de buscar terrenos fuera de Bilbao para su habilitación. De las diversas ofertas que se presentaron, la comisión evaluadora se inclinó por la propuesta ofrecida por Emiliano Olano, presidente del Consejo de Administración del ferrocarril Bilbao-Lezama y poco después alcalde de Bilbao (1894-1896). Era de valorar por su coste económico, dado que proponía la cesión gratuita de $112.500 \mathrm{~m}^{2}$ en Vista Alegre, jurisdicción de Zamudio y Derio, por sus condiciones favorables para la salud pública y por sus buenas comunicaciones, tanto por carretera como por ferrocarril, al ser próxima la inauguración de la línea ferroviaria Bilbao-Lezama (1892). En agosto de 1892 se presentaba para aprobación del gobierno el expediente de construcción del nuevo cementerio de Vista Alegre, en base a un presupuesto de 140.000 pts. La obra se retrasó a la espera de diversos análisis sobre la calidad del terreno, obra que quedó bajo la dirección del arquitecto Enrique Epalza y fue inaugurada en 1902.

Asimismo, la nueva red de infraestructuras urbanas y terciarias conllevó la reestructuración y reglamentación de los servicios públicos que, con el fin de alcanzar una gestión más ágil, derivaron, en ciertos casos, hacia una mayor centralización, en otros hacia la autonomía. Mayor autonomía se les reconoció a las Juntas de Caridad del Hospital y de la Casa de Misericordia. De hecho, la construcción del nuevo hospital, que pasó a tener un carácter provincial, supuso la separación del cuerpo médico municipal y el hospitalario. Aquel se limitó a la beneficencia municipal y servicios especiales (higiene pública, casa de socorro, reconocimiento de cadáveres y asistencia domiciliaria) y pasó a ser competencia de la Junta de Caridad del Hospital la organización del servicio médico hospitalario. Similar objetivo se planteaba con la reforma de la beneficencia domiciliaria (1896), en el intento de crear «una institución, con vida suficiente para cumplir debidamente los fines que le son propios», semejante a las anteriores. Sin embargo, con la entrada en servicio de la nueva Alhóndiga $\mathrm{Mu}-$ nicipal de Bilbao (1909) ${ }^{77}$, gran depósito y almacén de mercancías sujetas

77 A.H.F.B. Municipal Bilbao. Bilbao Hacienda 0033/001 y Bilbao Quinta 0133/022 (1904). El informe del concejal Pedro Bengoa, vocal de la comisión de Hacienda, fue decisivo para la puesta en marcha del proyecto, dado el estado ruinoso de las cinco alhóndigas existentes, la más reciente y principal, la de Barroeta Aldamar, construida en 1897. 
a impuesto municipal, se centralizaba la recaudación de determinados arbitrios, aumentando las medidas de inspección y control para su cobro, como no podía ser de otra manera, dado que los arbitrios constituían la base de los ingresos municipales.

\subsection{El tardío servicio de agua potable}

Hasta comienzos de los años 30, Bilbao no pudo contar con un servicio de agua de calidad al alcance de los ciudadanos. Pese a la incorporación del manantial «Ventaco-Erreca» y la construcción de la central y depósitos de Miraflores (1886), la red de abastecimiento de agua continuaba siendo insuficiente. En 1890 era aprobado el proyecto de traída de aguas del manantial de Larrumbe, al tiempo que se iniciaba la construcción de un nuevo depósito en Bolintxu, con capacidad para $16.000 \mathrm{~m}^{3}$.

Entretanto, el Ayuntamiento procedía también a regularizar el servicio de aguas, bajo las condiciones publicadas el 16 de diciembre de $1892^{78}$, fundamentalmente la obligatoriedad de la suscripción a ambas aguas, potable y de río, a caño libre. El servicio de agua potable a domicilio había seguido una «larga peregrinación» desde 1870, entonces, con las nuevas disposiciones, llevaría a nuevos gastos de instalación y al aumento del pago de cada suscriptor, de 10 ó de 20 pts. al año. Pero, también surgía el temor ante el manifiesto incremento que se advertía de las suscripciones de agua de la ría para su utilización en lavaderos, ascensores y demás, 3.500 llaves que se habrían de colocar siguiendo el acuerdo aprobado por la corporación municipal. Si ya era deficiente el suministro de agua de la ría, con la ampliación de estas instalaciones lo sería aún más, incidiendo negativamente en materia de saneamiento.

En definitiva, como concluye P. Novo, un recurso, el del agua, caro y desigualmente distribuido en función de las posibilidades económicas de los habitantes. Sólo una minoría de la población gozaba de fontanería pro-

Ello acarreaba tres problemas: la imposibilidad de ejercer una severa fiscalización municipal, dada la dispersión, el cuantioso gasto municipal para su sostenimiento y en personal, y el obstáculo para el comercio bilbaíno, siendo frecuentes las reclamaciones por el mal estado y/o las confusiones en la manipulación de los géneros.

78 El Noticiero Bilbaíno, 16 de diciembre de 1892. 
pia en sus hogares en torno a aquella fecha de $1893^{79}$. Teniendo en cuenta que el total de grifos de agua potable instalados en las habitaciones particulares ascendía a 3.974, a los que habría que sumar otros 400 montados en diversos negocios y 96 adscritos a los servicios municipales, como también que el número de edificios destinados a vivienda era de $2.457 \mathrm{y}$ 83.306 los habitantes censados (1900), se obtiene una media de un grifo por cada 21 habitantes o 1,6 por cada inmueble. Escaso número de abonados debido a la carestía del servicio e instalaciones, de manera que «la mayoría de la población dispondría, en el mejor de los casos, de una [instalación] comunitaria situada en el portal o patio del edificio, utilizada para el servicio de los inquilinos, en cuyo caso era el propietario del inmueble el único abonado». De todas formas, los suministros existentes tan sólo permitirían abastecer regularmente 7 u 8 meses al año, siempre que no fuesen pisos elevados, y en época estival el servicio se reducía a 3 o 4 horas diarias. El recurso para quienes no podían disponer de instalaciones propias o comunitarias era acudir a las fuentes públicas existentes.

Tras la epidemia de cólera, en 1894 la comisión municipal de Industria reclamaba medidas para regular el consumo de agua potable, definitivamente en agosto de dicho año se decidía la modificación del artículo 7. ${ }^{\circ}$ del Reglamento de aguas y se obligaba al uso de agua potable por contador y no a caño libre. Asimismo, se iniciaba la búsqueda de nuevos recursos, aprobándose el estudio de una ley que reconociese la utilidad pública de los manantiales de Oiz.

En paralelo, discurría el problema del saneamiento y los vertidos a la ría. La corporación municipal realizaba una llamada de atención sobre la escasa operatividad de la Junta especial para limpieza de la ría, constituida en $1885^{80}$, argumentando al respecto la dificultad de sus miem-

79 Novo, P. A. «iAgua, más agua!.. Bilbao 1850-1970», en J M. ${ }^{a}$ Beascoechea, M. González Portilla y P. A. Novo, La ciudad contemporánea, espacio y sociedad, Universidad del País Vasco-Universidad Autónoma de Puebla, Bilbao, 2006, p. 655.

${ }^{80}$ Fue miembro de la misma José María Solaun, teniente de alcalde de la corporación municipal presidida por Celestino Ortiz de la Riva (1887-1889) y más tarde Alcalde de Bilbao (1891). Actuó entonces como vocal del Ayuntamiento en la Junta de Obras del Puerto e inspector permanente de los depósitos de agua radicados en Miraflores y de la maquinaria de la isla de San Cristóbal (1887). Defendió el proyecto de saneamiento de la ría, propuso su dragado y la construcción de colectores que expulsasen lejos de la población dichos vertidos. Ver S. Serrano, «Solaun Mugaburu, José María», en J. Agirreazkuenaga (Dir.), Bilbao desde sus alcaldes. Diccionario Biográfico de los alcaldes de Bilbao y gestión municipal en tiempos de revolución liberal..., op. cit., pp. 573-578. 
bros para reunirse. Ante el riesgo que entrañaba para la salud pública el aumento de vertidos urbanos e industriales a dicho cauce, se proponía, una vez más, el dragado de la ría, así como la construcción de colectores que evacuaran los residuos lejos de la población. De todas formas, el problema era más complejo, al advertirse la deficiente calidad del agua potable, que se mezclaba con la de la ría a causa del mal estado de los filtros. Tras la inspección de los depósitos de Miraflores, que evidenció la mezcla de aguas y la existencia de partículas peligrosas, los informes emitidos en 1892 fueron concluyentes, declarando no potable y perjudicial para la salud el agua de la ría filtrada que era utilizada para beber. La población obrera la consumía por carecer las viviendas de suministro de agua potable, motivo que, unido a las deficiencias en la limpieza pública y en los servicios sanitarios y hospitalarios, hacía elevar la mortalidad a una tasa del 48,5 por mil en 1891, según el dato aportado por la corporación municipal ${ }^{81}$.

Sin duda, la actuación más concluyente fue la convocatoria a finales de 1891 de un concurso público para la construcción de una red de saneamiento y evacuación de residuos. Resultó vencedor el titulado «Mens sana in corpore sano», obra del ingeniero Recaredo Uhagón. Su propuesta contemplaba la construcción de una nueva red de alcantarillas, colectores y sifones hasta llegar al depósito regulador de Zorrozaurre y, por otro lado, las obras de dicho depósito, máquinas y cañerías que concluían en Punta Galea (Getxo), desde donde las mareas sacarían los vertidos sin afectar a las playas de la costa, obras estimadas en 3.600.000 pts. De esta forma, se obtenía una red separativa con recogida de todas las aguas residuales y vertido posterior al mar, que constituiría el nuevo alcantarillado, dejando la antigua red para el drenaje de la escorrentía pluvial, que continuó desaguando directamente a la ría. Tras quince años en los que el aumento de vertidos había sido alarmante ${ }^{82}$, finalmente el 28 de marzo de 1895, era aprobado el proyecto de saneamiento

81 Dicho dato, sin embargo, contrasta con las tasas brutas de mortalidad proporcionadas en M. González Portilla (Dir.), Bilbao en la formación del País Vasco..., op . cit., p. 236, elaboradas a partir de los censos y registro civil y parroquial, que oscilan en Bilbao de un 29,9 por mil en 1887 a un 32,59 por mil en 1900 .

${ }^{82}$ Un estudio más exhaustivo de de los planes de saneamiento en el área metropolitana bilbaína se encuentra en P. A. Novo y S. Serrano, «Cien años de saneamiento en la Ría de Bilbao (1900-2000)», en C. Contreras y Cl. Pardo (Eds.), La modernización urbana en México y España siglos XIX y XX, Benemérita Universidad Autónoma de Puebla y Universidad del País Vasco, Puebla, 2009, pp. 211-234. 
de Recaredo Uhagón ${ }^{83}$, que se encargó de la dirección de las obras, concluidas en ocho años. Asimismo, formuló el reglamento que pasó a regir la construcción de retretes y desagües de aguas negras de las viviendas de la villa, en base al mismo resultaba obligatoria la colocación de retretes en viviendas y habitaciones de alquiler, así como el uso de sifones en los mismos (26.06.1896).

Otro foco importante de contaminación por los vertidos practicados y su utilización como lavadero público era el arroyo Elguera, que discurría al descubierto a través del Ensanche. En 1891 se formó el proyecto para su alcantarillado, que fue desarrollándose en fases sucesivas. Más tarde, con la construcción de los dos lavaderos de San Mamés y Castaños (1905-1907), se irían desterrando estas prácticas, lavaderos obra del arquitecto municipal Ricardo Bastida, que se basó en modelos alemanes.

De ahí que, en los presupuestos del ejercicio de 1898-1899, el capítulo de gastos se elevara a 7 millones de pts., constituyendo la partida más elevada la destinada a obras públicas, 3.144 .559 pts., es decir, el 44, 92\%; en concreto, las de nueva construcción ascendían a 2.700 .000 pts. $(38,57 \%)^{84}$, al hallarse en marcha la ejecución de la red de saneamiento, las obras de la maquinaria de la isla San Cristóbal y otras accesorias del servicio de aguas, el hospital, el cementerio, el nuevo gasómetro, la Casa Galera o centro de acogida. El Ayuntamiento debía recurrir a un nuevo empréstito de 5 millones de pts. para obras de nueva construcción, así como a la creación y el aumento de impuestos, cuya repercusión social fue especialmente sentida en el caso de los consumos, el aumento de cuotas por servicio de aguas de río a domicilio y el llamado impuesto de «huecos» y apertura de establecimientos públicos. La intermediación de la Cámara de Comercio no sirvió para eliminar éste último, su cobro alcanzó el «carácter de motín» y se debió recurrir a los cuerpos locales de seguridad.

${ }^{83}$ R. Uhagón, Proyecto definitivo de saneamiento de la Villa de Bilbao, Madrid, 30 de diciembre de 1893.

${ }^{84}$ S. Serrano, «Alonso de Celada Las Carreras, Felipe», en J. Agirreazkuenaga (Dir.), Bilbao desde sus alcaldes. Diccionario Biográfico de los alcaldes de Bilbao y su gestión municipal en tiempos de revolución liberal..., op. cit., pp. 631-632. 


\section{Tabla 5}

Agua potable 1./día/persona en 1900 (83.300 habitantes)

\begin{tabular}{lcccc}
\hline \multicolumn{1}{c}{ Manantiales } & Estiaje & Total 1./día & Total - Pérdidas (25\%) & 1./día/persona \\
\hline Uzcorta & $51 . / s$. & 432.000 & 324.000 & 3,9 \\
Abrisketa & $21 . / s$. & 172.800 & 129.600 & 1,6 \\
Ventaco-Erreca & $71 . / \mathrm{s}$. & 604.800 & 453.600 & 5,4 \\
Larrumbe & $141 . / \mathrm{s}$ & 1.209 .600 & 907.200 & 10,9 \\
\hline Total & $281 . / \mathrm{s}$. & 2.419 .200 & 1.814 .400 & 21,8 \\
\hline
\end{tabular}

Fuente: ES 48020 AMB-BUA 313530 (26.05.1904).

En cuanto a la captación de nuevos suministros, desde la traída de aguas de Larrumbe en 1893 nada se había avanzado, todos habían sido proyectos frustrados (Oiz, Cerneja y Ventorrillo, Gorbea), y el déficit presupuestario había terminado por encallar la situación. A comienzos de la década de los años veinte Bilbao disponía de 150 l./s. de agua potable durante seis o siete meses al año, pero durante el estío se reducía a 65-70 1. Y la población continuaba en ascenso, en torno a los 115.000 habitantes en 1920, a los que habría que sumar en 1925 los 20.000 derivados de las anexiones de Begoña, Deusto y Lutxana (Erandio).

Por esas fechas, se construía el embalse de Zollo (1923), con capacidad para $400.000 \mathrm{~m}^{3}$, pero tampoco era la solución. Todavía entonces el consumo del agua de la ría rondaba los 320 litros al día por persona, frente a los 50 de agua potable. Mientras el Estatuto Municipal de 1924 establecía la obligatoriedad para los municipios de más de 15.000 habitantes de disponer de un suministro de 200 1./s./día, de calidad química y bacteriológica garantizadas. En cumplimiento con lo establecido y con los acuerdos adoptados por la corporación municipal, su alcalde, Federico Moyua, solicitaba en 1925 el aprovechamiento de aguas de los ríos Cerneja y Ordunte, otorgado por R.O. de 20 de enero de 1928. Las obras finalizaron en 1933, 40 millones de pts., que fueron costeadas en su totalidad por el Ayuntamiento y se dispuso ya de aguas de calidad. 


\section{Reflexiones finales}

Equipamientos y servicios públicos no formaron parte únicamente del discurso programático de quienes se hallaban al frente de la administración local bilbaína, sino que ocuparon un primer plano en la gestión de la corporación municipal desde el último cuarto del siglo XIX. Pablo Alzola sentó las bases y líneas de actuación a seguir dentro de su programa, aunque, por modestia, como expresara él mismo, no lo quiso calificar como tal, pero de hecho marcó la pauta para las corporaciones venideras. Eduardo Victoria de Lecea formuló el primer plan de obras públicas, con propuestas más concretas que se fueron negociando y resolviendo en la década posterior. Obviamente, ello no obstó para que importara más el crecimiento económico de las actividades comerciales e industriales en la ciudad, que sin duda eran las preocupaciones de las élites influyentes. La mayoría de los alcaldes del período 1876-1900 pertenecía al grupo de la burguesía (o bien patrimonialista o bien funcional con formación técnica) y participaban de la corriente monárquico-liberal organizada en partidos de ámbito estatal. En sus relaciones con el gobierno central y los líderes políticos intercedieron preferentemente por el desarrollo del puerto y los negocios industriales y ferroviarios.

Actuaron como agravantes los problemas derivados de las elevadas tasas de crecimiento demográfico y de mortalidad, de la propagación de epidemias, del aumento de la beneficencia..., difíciles de prever, lo que obligó a aplicar simples medidas de urgencia. Como también lo fue la escasez de recursos de la hacienda local, endeudada por los gastos de la guerra, del Ensanche, de las obras públicas, del aumento de personal y de las anexiones de las anteiglesias de Abando y Begoña. Asimismo, en este espacio de la ciudad se sumaron las estrategias de los propietarios de terrenos, con quienes hubo que negociar, dado que su participación era necesaria para llevar a cabo el Ensanche al haber renunciado la villa a la contribución directa cedida por el Estado. Dilatadas negociaciones que no faltaron tampoco en el momento de encontrar terrenos donde levantar los grandes equipamientos de la ciudad.

La configuración de una red de servicios públicos, con instalaciones construidas ex profeso, bajo presupuestos modernos y con carácter definitivo, no se materializó hasta finalizar la década de los años diez, cuando también surgieron las primeras iniciativas para abordar el gran problema de la vivienda barata. En 1918, se constituyó la institución Casa Baratas 
de Bilbao, bajo la presidencia del alcalde Mario Arana, proyecto que asumió el arquitecto municipal Ricardo Bastida. Entre 1918 y 1920 se levantaron los grupos de vivienda de Solokoetxe ${ }^{85}$ y Torre Urizar ${ }^{86}$, ambos en la periferia de la ciudad, que ponían a disposición de la población más de 300 viviendas de alquileres baratos. Desde 1920 el ayuntamiento no emprendió más construcciones, de manera que ambos grupos quedaban enmarcados dentro de la primera etapa desarrollada por el Ayuntamiento de Bilbao para paliar el problema de la vivienda obrera.

En los años venideros hasta la guerra, los retos y debates se centraron de forma preferente en la reforma interna de la ciudad, la vialidad, los enlaces y las comunicaciones externas, así como la ordenación de la infraestructura ferroviaria. La oportunidad vino de la mano del proyecto diseñado por el arquitecto Secundino Zuazo, así como del Plan de accesos a Bilbao y de las propuestas de la Comisión de Enlaces ferroviarios, éstos últimos elaborados por Ricardo Bastida, todos ellos una oportunidad perdida.

85 El ayuntamiento ya en 1910 había encargado a Ricardo Bastida el estudio de un barrio obrero en este mismo enclave. La primera piedra del proyecto definitivo de Solokoetxe se colocaba el 11 de octubre de 1918.

86 Viviendas económicas. Labor del Municipio bilbaíno en la resolución de la vivienda económica, Ayuntamiento de Bilbao, Bilbao, 1949. Tres días después de la colocación de aquella primera piedra de Solokoetxe, la Junta adquiría una parcela de terreno junto a la antigua Casa Torre de Urizar y, al finalizar el año, se anunciaba ya que, de nuevo, Ricardo Bastida se encargaría de este segundo proyecto de vivienda barata. El Grupo de Torre Urizar iniciaba su edificación en mayo de 1919, grupo que se componía de 264 viviendas y 11 lonjas, de renta media anual de 32 pts. y destinadas a albergar a una población de 1.381 personas. 